\title{
Composition of the core and implications for origin of the earth
}

\author{
A. E. RINGWOOD \\ Research School of Earth Sciences, Australian National University, Canberra, Australia
}

(Received March 7, 1977; accepted in revised form April 25, 1977)

\begin{abstract}
The density of the core is about 8 percent smaller than that of pure iron under similar $\mathrm{P}, \mathrm{T}$ conditions, implying the presence of a substantial amount of light element(s). Sulphur is popularly considered to be the principal light element in the core. If so, the earth accreted about 44 percent of the primordial complement of this element. To accrete sulphur as efficiently as this, and at the same time, to account for the observed depletions by much larger factors of $\mathrm{Na}, \mathrm{K}, \mathrm{Mn}, \mathrm{Rb}, \mathrm{F}, \mathrm{Cs}, \mathrm{Zn}$ and $\mathrm{Cl}$, the earth must have accreted in an environment where hydrogen was depleted relative to sulphur by a factor of about 100 , compared to the solar nebula. The conditions required are restrictive and encourage evaluation of other light elements as possible components of the core, for example, oxygen.

Experimental observations show that the solubility of $\mathrm{FeO}$ in liquid iron increases rapidly between 1,500 and $2,000^{\circ} \mathrm{C}$. Thermodynamic extrapolation of solubility data implies solubility of $40 \mathrm{~mol} . \%$ $\mathrm{FeO}$ at $3,000^{\circ} \mathrm{C}$ and complete miscibility of liquid $\mathrm{Fe}$ and $\mathrm{FeO}$ above $3,500^{\circ} \mathrm{C}$. Calculations show that solubility is greatly increased by high pressures and that at $2,500^{\circ} \mathrm{C}$, the liquid metal phase in equilibrium with the probable mineral assemblage in the lower mantle $(\mathrm{FeO} /(\mathrm{FeO}+\mathrm{MgO})=0.12$ ) would contain more than $50 \mathrm{~mol} . \% \mathrm{FeO}$ at a pressure of $300 \mathrm{~kb}$, and would be about 10 percent less dense than pure iron. These results imply that $\mathrm{FeO}$ is probably a major constituent of the earth's core.

Solubility of $\mathrm{FeO}$ in metal may be accompanied by a large increase in oxygen fugacity of the coremantle system relative to the situation where solution of $\mathrm{FeO}$ in molten iron does not occur. This effect is enhanced by the pressure-induced partial disproportionation of $\mathrm{Fe}^{2+}$ into $\mathrm{Fe}^{3+}+\mathrm{Fe}^{0}$ in the lower mantle. Accordingly, the distribution of siderophile elements between mantle and core and the occurrence of oxidized species such as $\mathrm{H}_{2} \mathrm{O}, \mathrm{CO}_{2}$ and $\mathrm{Fe}^{3+}$ in the mantle could result from attainment of local chemical equilibrium at high pressures between $(\mathrm{Fe}-\mathrm{FeO})$ metal and silicate phases in the more oxidizing environment prevailing during core segregation. Models of greater complexity, involving heterogeneous accretion of the earth and chemical disequilibrium between metal and silicate phases may not be necessary. Thus, if $\mathrm{FeO}$ indeed enters the core as suggested, rather simple models whereby the earth formed by homogeneous accretion from a mixture consisting of $10 \%$ of low-temp. oxidized primordial condensate similar to $\mathrm{C} 1$ chondrites $\left(20 \% \mathrm{H}_{2} \mathrm{O}\right)$ and $90 \%$ of devolatilized, reduced material (mainly metallic iron and magnesium silicates) can provide a satisfactory explanation of the earth's bulk composition.
\end{abstract}

\section{INTRODUCTION}

The composition of the earth's core continues to arouse discussion and debate. Comprehensive reviews on this topic have recently been published by JACOBS (1975) and BRETT (1976) and particular aspects have been further considered by BIRCH (1972), BULLEN (1973a), BUKOWINSKI (1976) and ITO (1976). There is now a widespread consensus that the core is dominantly composed of metallic iron contain- ing some nickel (BIRCH, 1963, 1964, 1972). Meteoritic abundance estimates suggest the presence of about $6 \% \mathrm{Ni}$. However, the density of the outer core appears to be about 8-10 percent smaller than would be expected for pure iron under equivalent $\mathrm{P}, \mathrm{T}$ conditions, whilst the hydrodynamical sound velocity of the core also appears to be substantially higher than expected for pure iron (e.g., BIRCH, 1952, 1972; KNOPOFF and MaCDonald, 1960; Clark and Ringwood, 1964; MCQUeEN and MARSH, 1966). These 
properties have been generally interpreted to imply that the core contains about 10 to 20 percent of an element or elements of low atomic weight, e.g., $\mathrm{H}, \mathrm{C}, \mathrm{N}, \mathrm{O}, \mathrm{Mg}, \mathrm{Si}, \mathrm{S}(\mathrm{BIRCH}, 1952$, 1964; BRETT, 1976).

RINGWOOD (1966a) argued that the first four of these elements were unlikely candidates since they form interstitial solutions with metallic iron, dominantly occupying holes already present in the lattice and therefore having only a small effect upon density. I now believe that this argument may not be valid in the cases of $\mathrm{C}, \mathrm{N}$ and $\mathrm{O}$ under the high pressures existing in the core. The atomic radii of $\mathrm{C}(0.77 \AA)$, $\mathrm{N}(0.74 \AA)$ and $\mathrm{O}(0.74 \AA)$ lie almost exactly at the upper limit possible for interstitial solid solution in metallic iron $(1.27 \AA)$ which is reached when the radius ratio of interstitial atom to metal is 0.59 . The densities within the outer core imply a contraction in average radius of the iron atoms of just over 10 percent. The corresponding contraction in the case of the smaller interstitial atoms would be much smaller (RINGWOOD, 1975, p. 355), so that the critical radius ratios for interstitial solution would be exceeded in the cases of $\mathrm{C}, \mathrm{N}$ and $\mathrm{O}$. These atoms would, therefore, be likely to form dominantly substitutional solutions, although, because of the disordered liquid state, a significant fraction might well occupy interstitial sites at a given instant. Nevertheless, providing that most of these atoms formed substitutional solutions, their addition would cause net reductions in the mean densities of the systems.

It seems, therefore, that we cannot choose between $\mathrm{C}, \mathrm{N}, \mathrm{O}, \mathrm{Mg}, \mathrm{Si}$ and $\mathrm{S}$ as possible components of the outer core solely on physical or crystallographic grounds. If the alternatives are to be further restricted, chemical evidence must be introduced. Arguments have been advanced in favour of several of the above light elements in the past and we will review these in later sections. Currently, considerable support has developed in favour of the view that sulphur is the most likely to be the principal light element in the core (e.g. GoldSCHMIDT, 1922; Mason, 1966; Murthy and Hall, 1970; ANDERson, et al., 1971; and many others). This hypothesis has frequently been linked with the proposal that most of the earth's potassium is present in the core (MURTHY and HaLl, 1970; LEwIS, 1971). The implications of these interpretations for theories of the origin and thermal evolution of the earth are profound. Accordingly, it seems appropriate to commence our discussion with an examination of the case for the presence of sulphur (and potassium) in the core.

\section{Sulphur IN THE CoRE}

(a) Some general considerations AHRENS (1976) has examined the composition of the earth's outer core in the light of shock wave data on the densities of $\mathrm{FeS}, \mathrm{Fe}$ and $\mathrm{Ni}$ under very high pressures. Assuming that the additional light element in the core is sulphur, he finds that about 14 weight percent of this element would be necessary to account for the lower density of the outer core as compared to that of a pure iron-nickel alloy of appropriate composition. This is equivalent to 4.5 percent of sulphur in the bulk earth and implies that the earth must have accreted about 44 percent of the primordial abundance of sulphur, assuming the latter to be given by Type 1 (C1) carbonaceous chondrites.

In the parental solar nebula, sulphur would be condensed as FeS only at temperatures below $650^{\circ} \mathrm{K}$ (Table 1). Nearly all metals are fully condensed at temperatures higher than this (exceptions are $\mathrm{Pb}, \mathrm{Bi}, \mathrm{In}$ and $\mathrm{Tl}$ ). Sulphur is thus an extremely volatile element in a nebula of solar composition. Moreover, at temperatures below $400^{\circ} \mathrm{K}$, thermodynamic data show that magnetite becomes stable relative to troilite (Grossman and Larimer, 1974). This is also demonstrated by the mineralogy of the equilibrated C3 chondrite Karoonda (MASON and WIIK, 1962) which displays the assemblage: olivine + pyroxene + plagioclase + magnetite + pentlandite, and contains only $1.6 \% \mathrm{~S}$ (as compared to $\sim 2 \% \mathrm{~S}$ present as troilite, $\mathrm{FeS}$, in ordinary metal-containing chondrites). Thus, sulphur can be condensed as FeS only in a narrow temperature interval between 650 and $400^{\circ} \mathrm{K}$.

Studies of the composition of the earth's mantle provide strong evidence that it is depleted in a wide range of elements compared to the primordial abundances as provided by Type 1 (C1) carbonaceous chondrites. These include Rb (GAST, 1960), K (Clark and Ringwood, 1964; WaSSERBURG et al., 1964) and $\mathrm{Zn}, \mathrm{Cd}$, $\mathrm{Hg}, \mathrm{Ge}, \mathrm{Tl}, \mathrm{Pb}, \mathrm{Bi}, \mathrm{In}, \mathrm{F}, \mathrm{Cl}$ (R INGwood, 1966a, b). A more detailed study of the abundances of a wider range of volatile elements in the earth's mantle was carried out by RINGwOOD and KESSON (1977) and is shown in Fig. 1. The significant feature is that many elements pos- 
Table 1.

Condensation temperatures and sequence of phases and elements separating from gas of solar composition at $10^{-4}$ atmospheres total pressure. Temperatures correspond to 50 percent condensation of a given element. (Based on GROSSMAN and LARIMER, 1974, Fig. 2; GROSSMAN, 1972; ANDERS, 1968; Fig. 5; WASSON and WAI, 1976; and WAI and WASSON, 1977).

\begin{tabular}{|c|c|}
\hline Element or Compound & ${ }^{\circ} \mathrm{K}$ \\
\hline $\begin{array}{l}\mathrm{Ca}, \mathrm{Al}, \mathrm{Ti} \text { oxides and silicates } \\
\text { Platinum metals, W, Mo, Ta, } \mathrm{Zr}, \mathrm{REE}\end{array}$ & $>1,400$ \\
\hline $\mathrm{Mg}_{2} \mathrm{SiO}_{4}$ & $\sim 1,360$ \\
\hline $\mathrm{Fe}-\mathrm{Ni}$ metal & $\sim 1,360$ \\
\hline Remaining $\mathrm{SiO}_{2}$ (as $\mathrm{MgSiO}_{3}$ ) & $1,200-1,350$ \\
\hline $\mathrm{Cr}_{2} \mathrm{O}_{3}$ & - \\
\hline$P$ & 1,290 \\
\hline $\mathrm{Au}$ & 1,230 \\
\hline $\mathbf{L i}$ & 1,225 \\
\hline $\mathrm{Mn}_{2} \mathrm{SiO}_{4}$ & 1,190 \\
\hline As & 1,135 \\
\hline $\mathrm{Cu}$ & 1,118 \\
\hline $\mathrm{Ga}$ & 1,075 \\
\hline$(\mathrm{K}, \mathrm{Na}) \mathrm{AlSi}_{3} \mathrm{O}_{8}$ & $\sim 1,000$ \\
\hline $\mathrm{Ag}$ & 952 \\
\hline $\mathrm{Sb}$ & 910 \\
\hline $\mathrm{F}$ & 855 \\
\hline $\mathrm{Ge}$ & 812 \\
\hline $\mathrm{Sn}$ & 720 \\
\hline $\mathrm{Zn}$ & $660-760$ \\
\hline $\mathrm{Se}$ & 684 \\
\hline $\mathrm{Te}$ & 680 \\
\hline $\mathrm{Cd}$ & 680 \\
\hline $\mathrm{S}$ (as $\mathrm{FeS})$ & 648 \\
\hline $\mathrm{FeO}\left(10 \%\right.$ ss. as $\left.\left(\mathrm{Mg}_{0.9} \mathrm{Fe}_{0.1}\right)_{2} \mathrm{SiO}_{4}\right)$ & $\sim 600$ \\
\hline $\mathrm{Pb}$ & 520 \\
\hline $\mathrm{Bi}$ & 470 \\
\hline In & 460 \\
\hline $\mathrm{T1}$ & 440 \\
\hline $\mathrm{Fe}_{3} \mathrm{O}_{4}$ & 400 \\
\hline $\mathrm{NiO}$ & - \\
\hline $\mathrm{H}_{2} \mathrm{O}$ (as hydrated silicates) & $\sim 300$ \\
\hline
\end{tabular}

* Significant differences appear in calculations by the authors cited. We have selected what appear to be the most reliable estimates based upon recent thermodynamic data.

sessing highly diversified chemical properties are depleted in the mantle by factors ranging from 1.3 to over 100 .

The general sequence of increasing depletion factors (Fig. 1) corresponds quite well to the sequence of condensation of elements and phases from a cooling gas of solar composition (Table 1) and strongly suggests that the terrestrial depletions are primarily a consequence of selective condensation/volatilization processes. In the cases of some elements (e.g., $\mathrm{Cu}$, $\mathrm{As}, \mathrm{Au}, \mathrm{Ge}, \mathrm{S}, \mathrm{Se})$, depletions in the mantle are

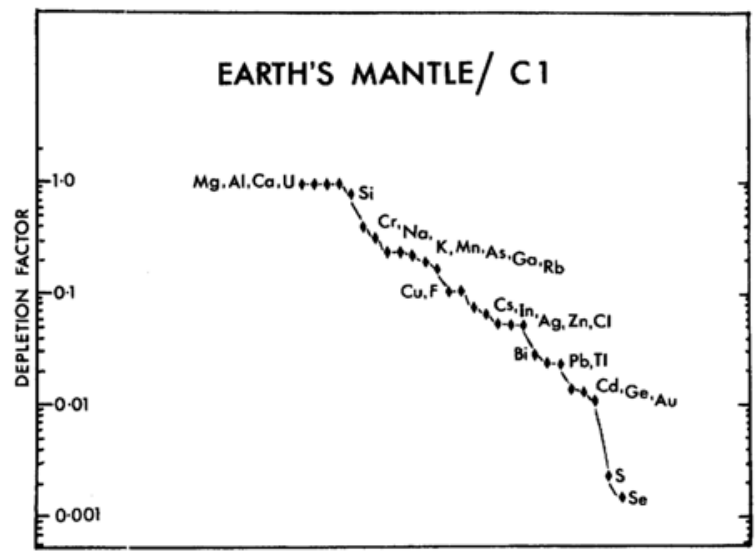

Fig. 1. Abundances of elements (normalized to $\mathrm{Mg}$ ) in the earth's mantle compared to primordial abundances as given by Cl chondrites (after RINGWOOD and KESSON, 1977). The strong depletions of $S$ and Se in the mantle are not necessarily characteristic of the entire earth since these elements are likely to be strongly concentrated in the core.

also caused in part by their siderophile nature which has resulted in preferential entry into the earth's core.

A formidable problem confronting the hypothesis that sulphur is the principal light element in the earth's core lies in explaining why such a highly volatile element is not as depleted in the bulk earth as several non-siderophile elements which are much less volatile than sulphur in the solar nebula. For example, $\mathrm{Cr}, \mathrm{Na}, \mathrm{K}, \mathrm{Mn}, \mathrm{Rb}$, $\mathrm{F}, \mathrm{Cs}, \mathrm{Zn}$ and $\mathrm{Cl}$ are all less volatile than $\mathrm{S}$ (Table 1) and yet appear to be depleted in the earth by larger factors. Depletion factors (DF) of these elements compared to the primordial $\mathrm{Cl}$ and solar abundances range from 0.3 to 0.03 as compared to the terrestrial depletion factor for sulphur of 0.44 .

The problem of retaining sulphur whilst losing less volatile elements is highlighted by the compositions of meteorites. In the chemical processing by which the ordinary chondrites were formed from primordial material, about $80 \%$ of the sulphur was lost, but $\mathrm{Na}, \mathrm{K}$ and $\mathrm{Rb}$ remained essentially intact. The highly oxidized, metal-free assemblage of the Karoonda C3 equilibrated chondrite indicates that it condensed at lower temperatures than ordinary chondrites, yet its sulphur content is smaller. Moreover, iron meteorites contain, on the average, only about one percent of sulphur yet most evidently formed in an environment (prior to metal segregation) where $\mathrm{Na}, \mathrm{K}$ and $\mathrm{Rb}$ were un- 
depleted, as indicated by the compositions of silicate inclusions found in iron meteorites.

Among meteorites forming in high temperature environments, only some of the enstatite chondrites successfully condensed a large proportion of the primordial abundance of sulphur. The reason for this, however, was that they formed in a chemical environment which differed drastically from that of the solar nebula composition. In particular, hydrogen was strongly depleted relatively to $\mathrm{H}_{2} \mathrm{~S}$ whilst $\mathrm{C}$ was strongly enriched relatively to $\mathrm{H}_{2} \mathrm{O}$ (RINGWOOD, 1966c; LARIMER, 1975). We will return to this topic subsequently.

\section{(b) Potassium in the core}

LEWIS (1971)

and HALL and MURTHY (1971) have recognized the difficulties inherent in retaining sulphur whilst losing less-volatile elements during accretion of the earth and have proposed an interesting solution. They suggest that the earth accreted mostly under low-temperature conditions so that elements such as $\mathrm{K}$ and $\mathrm{Rb}$ were fully condensed, whilst sulphur was substantially condensed. The bulk earth is believed to possess approximately an ordinary chondritic composition (LEwIS). It is claimed, however, that $\mathrm{K}$ and $\mathrm{Rb}$ were actually chalcophile under coreforming conditions and, accordingly, became preferentially partitioned into the sulphide phase which entered the core, thereby leaving the mantle depleted in these elements as observed.

This hypothesis has been the occasion of considerable debate and recent reviews, e.g., JACOBS (1975), BRETT (1976) have adopted a somewhat equivocal position. Because of the far-reaching geothermal and cosmochemical implications of this hypothesis, if correct, further discussion is desirable.

The thermodynamic data used by LEwIS, HALL and MURTHY to justify the conclusion that potassium is a strongly chalcophile element were based upon highly simplified systems of doubtful relevance to the earth. Oversby and Ringwood (1972, 1973) experimentally measured the partition of potassium between Fe$\mathrm{FeS}$ and basaltic silicate melts and found that less than one percent of the potassium had entered the sulphide phase. Goetrel (1975) studied the distribution of potassium between orthoclase and FeS-Fe liquid, finding that the proportion of potassium which entered the sulphide phase was on the order of a few parts per thousand. These experiments demonstrated that potassium cannot be regarded in any sense as a chalcophile element.

Despite these unfavourable results, GoETTEL and LEWIS (1973) and GoETTEL (1975) continued to maintain that most of the earth's potassium had entered the core. To make this possible, they were obliged to postulate the existence of a very large positive temperature coefficient for the distribution coefficient of $\mathrm{K}$ between sulphide and silicate. The experimental data used to justify this distribution coefficient (GoETTEL, 1975 ) were extremely inadequate.* Yet another assumption (see also, RinGwOoD, 1975) was that potassium would initially be present as an independent $\mathrm{K}$-rich mineral in the deep mantle. (This assumption is necessary in order to maximize its thermodynamic activity in the mantle and likewise its entry into the sulphide phase.) However, BuKOwINSKI (1976) has recently shown that because of the very high compressibility of potassium, its ionic radius will be similar to that of common elements such as $\mathrm{Fe}^{2+}, \mathrm{Mg}^{2+}$, $\mathrm{Ca}^{2+}$ and $\mathrm{Na}^{+}$at pressures as low as $500 \mathrm{~kb}$. Thus, potassium is likely to be present as a very minor component (coupled with $\mathrm{Al}^{3+}$ ) in solid solution in major mantle minerals, rather than as an independent K-rich phase. The consequent lowering of its thermodynamic activity would be accompanied by a corresponding decrease in the proportion which entered the metalsulphide phase.

The abundance patterns of volatile elements in the earth's mantle, moon and meteorites provide key evidence relating to this problem. It has already been noted that the earth's mantle is depleted in a wide range of elements compared to primordial abundances (Fig. 1). The overall pattern leaves little doubt that these depletions were caused mainly by selective volatility or selective condensation. The depletions of $\mathrm{K}$ and $\mathrm{Rb}$ should be interpreted not in isolation, but in relation to the overall abundance patterns displayed by other volatile elements. Several volatile elements, e.g., $\mathrm{Na}, \mathrm{Mn}, \mathrm{Cr}, \mathrm{F}$, $\mathrm{Zn}, \mathrm{Cl}$, which are more depleted in the earth than in ordinary chondrites, are neither chalcophile nor siderophile at the redox state of the earth's mantle. It is improbable that these depletions have been caused by their preferential entry into the core.

* An attempt was made to determine distribution coefficients at two temperatures only $40^{\circ} \mathrm{C}$ apart. The scatter in individual determinations at either single temperature was very large in comparison with the difference in the means for each of these temperatures. 
The depletion of volatile elements is even more dramatic in the case of the moon. In particular, the alkali metals are depleted by factors of 3-10 compared to the earth's mantle (e.g., RingwOoD and Kesson, 1977) and the element most depleted is sodium, which has never been claimed to be chalcophile or siderophile (HALl and Murthy, 1971; LewIS, 1971). A lunar core, if present, is very small. Moreover, lunar low-Ti mare basalts which exhibit these abundance patterns were not saturated either with metallic iron or $\mathrm{FeS}$ in their source regions (SATO et al., 1973; RINGWOOD and Kesson, 1977). There is thus no possibility of explaining the depletions of alkali metals within the moon as compared to chondritic meteorites, in terms of partition in a lunar core.

Eucritic meteorites display volatile element depletion patterns qualitatively similar to the moon. These meteorites have formed on a separate parent body to the moon (TAYLOR et al., 1965) which must, however, have been much smaller. Potassium is present as a minor component in plagioclase, and not as a separate $\mathrm{K}$ rich mineral. In the light of known partition equilibria, there is no possibility that the depletion of alkali metals in eucrites was caused by entry into the core of their parent body. Likewise, the compositions of most classes of chondritic meteorites were strongly influenced by selective condensation/volatilization processes (ANDERS, 1971; Grossman and LARIMER, 1974). The alkali metals are among those which were fractionated by these processes which, again, had nothing to do with core formation.

The thrust of this discussion is to emphasize the generality of selective volatilization/condensation processes which have caused gross fractionations of elements among earth, moon, eucrites and the various classes of chondrites. The fractionations of $\mathrm{K}$ and $\mathrm{Rb}$ simply represent special cases of this general process. It is inescapable that the depletions of alkali metals and other volatile elements in the moon, eucrites and chondrites were caused not by entry into metal-sulphide phases but by volatility. Their depletions in the earth's mantle, including elements which are neither siderophile nor chalcophile, are clearly to be attributed to the same cause.

BUKOWINSKI (1976) has recently concluded on the basis of a theoretical study that at a pressure of $500 \mathrm{~kb}$, the ionic radius of potassium becomes similar to that of iron, whilst the electronic structure of potassium becomes like that of a typical transition metal. He points out that these properties should greatly enhance the miscibility of potassium in iron or iron sulphide melts, thereby making it possible for potassium to enter the core.

Accepting these arguments, it should nevertheless be noted that miscibility is a necessary but not sufficient condition to explain preferential partition of potassium in the core. The decisive properties are the relative chemical affinities of iron and high-pressure potassium for oxygen as exemplified by the equilibrium:

$$
\mathrm{K}_{2} \mathrm{O}+\mathrm{Fe}=\mathrm{FeO}+2 \mathrm{~K}_{(\mathrm{Fe})}
$$

BUKOWINSKI does not indicate the relative affinities of these metals for oxygen. It should be noted, however, that all of the transition metals possessing lower atomic numbers than iron $(\mathrm{Sc}$, $\mathrm{Ti}, \mathrm{V}, \mathrm{Cr}$ and $\mathrm{Mn}$ ) possess much higher affinities for oxygen than does iron. Accordingly, they behave as lithophile elements and do not enter the core. As a "light" transition metal, it seems quite likely that the high pressure form of potassium would resemble these transition elements in this respect. We note, also, that the depletions of potassium in the moon, in eucrites and in some classes of chondrites cannot be explained by the changed properties of potassium which are achieved only under very high pressure.

(c) Discussion On the basis of the preceding discussion, we reject the proposal that most of the earth's potassium (and other volatile elements) reside in the core. It appears almost certain that these are actually depleted in the bulk earth, compared to $\mathrm{Cl}$ and ordinary chondrites and that these depletions are direct consequences of their volatility. We must, therefore, acknowledge the very severe difficulties encountered by models which propose that the earth, accreting in a nebula of solar composition, condensed over 40 percent of the primordial complement of sulphur, but nevertheless lost much larger proportions of several elements which are much less volatile than sulphur. It does not seem possible to devise possible conditions of condensation and accretion within a nebula of solar composition by which sulphur is retained and these other elements lost. We are led, therefore, to consider conditions under which substantial quantities of sulphur could have become trapped within the earth accreting within a system of non-solar composition. 
(d) Condensation of sulphur and alkalis The condensation of sulphur is governed by the equilibrium:

$$
\mathrm{Fe}+\mathrm{H}_{2} \mathrm{~S} \rightleftarrows \mathrm{FeS}+\mathrm{H}_{2}, \quad K=\frac{\mathrm{H}_{2}}{\mathrm{H}_{2} \mathrm{~S}}
$$

Table 2. Condensation of sulphur according to equilibrium: $\mathrm{Fe}+\mathrm{H}_{2} \mathrm{~S}=\mathrm{FeS}+\mathrm{H}_{2}$

\begin{tabular}{lcc}
\hline $\mathrm{T}^{\circ} \mathrm{C}$ & $\mathrm{K}=\mathrm{H}_{2} / \mathrm{H}_{2} \mathrm{~S}$ & $\begin{array}{c}\text { Hydrogen depletion } \\
\text { factor }^{1}\end{array}$ \\
\hline 200 & $3.2 \times 10^{6}$ & $\mathrm{FeS}$ stable \\
400 & $3.3 \times 10^{4}$ & $\mathrm{FeS}$ marginally stable \\
600 & $2.6 \times 10^{3}$ & 12 \\
800 & $5.6 \times 10^{2}$ & 57 \\
900 & $3.2 \times 10^{2}$ & 100 \\
$988^{2}$ & $2.0 \times 10^{2}$ & 160 \\
\hline $1400^{\circ} \mathrm{C}$ & 100 & 320 \\
$\mathrm{Fe}_{0.8} \mathrm{~S}_{0.2}$ liquid & & \\
\hline
\end{tabular}

1 The hydrogen depletion factor is the factor by which hydrogen must be depleted in the solar nebula relative to sulphur, in order to permit the condensation of $\mathrm{FeS}$ at the given temperature. The primordial $\mathrm{H}_{2} / \mathrm{H}_{2} \mathrm{Sratio}$ is taken as $3.18 \times 10^{4}$ (CAMERON, 1973).

${ }^{2} \mathrm{Fe}-\mathrm{FeS}$ eutectic is at $988^{\circ} \mathrm{C}$.

Values of $K$ at various temperatures are calculated in Table 2 from the relationship $\Delta G=$ $-\mathrm{RT} \operatorname{\mathrm {n}} K$, where the free energy $\Delta G$ is obtained from standard thermodynamic data (KUBACHEWSKI and EVANS, 1958). In a gas phase of solar composition, troilite condenses near $650^{\circ} \mathrm{K}$ (W and W ASSON, 1977). We are interested in outlining conditions where FeS may condense, but where the alkali metals are volatilized. Experimental studies of the volatilization of $\mathrm{Na}, \mathrm{K}$ and $\mathrm{Rb}$ from mare basalt in high vacuum and at iron-saturation were reported by DE MARIA et al. (1971) and GIBSON et al. (1972). Sodium displays substantial volatility at $1,000^{\circ} \mathrm{C}$ whilst $\mathrm{K}$ and $\mathrm{Rb}$ volatilize at lower temperatures. Sodium is already strongly depleted in mare basalts compared to its primordial abundance so that it would probably evaporate from primordial material at temperatures appreciably lower than $1,000^{\circ} \mathrm{C}$. Grossman (1972) calculated that $\mathrm{Na}$ and $\mathrm{K}$ would condense as alkali felspar at $730^{\circ} \mathrm{C}$ in the solar nebula at $10^{-3} \mathrm{~atm}$. This temperature is too low in the present context, since it is shown below that a large reduction in the abundance of hydrogen is needed if $\mathrm{FeS}$ is to be condensed. This reduction increases the condensation temperature of alkalis. It seems most likely that the volatiliza- tion of $\mathrm{Na}$ and $\mathrm{K}$ would require minimum temperatures in the vicinity of $800-900^{\circ} \mathrm{C}$. Condensation of $\mathrm{FeS}$ under these conditions requires that the abundance of $\mathrm{H}_{2}$ relative to $\mathrm{S}$ in the solar nebula is reduced by a factor of about 100 compared to the solar ratio (Table 2).

The Fe-FeS eutectic is at $988^{\circ} \mathrm{C}$ (HANSEN and ANDERKo, 1968). Alkalis and other elements (e.g. Mn) may have been volatilized at higher temperatures than this during formation of the earth. If sulphur is to be retained under these conditions, we must consider the behaviour of $\mathrm{Fe}-\mathrm{FeS}$ solutions. The lowering of the activity of $\mathrm{FeS}$ in this solution tends to counteract the effect of higher temperatures in increasing the hydrogen depletion factors (Table 2) required for condensation of sulphur. The thermodynamic data of SHERman et al. (1950) and KUBACHEWSKI and Evans (1958) show that an $\mathrm{Fe}-\mathrm{FeS}$ solution containing 12 weight percent of sulphur would be in equilibrium with a gas having $\mathrm{H}_{2} / \mathrm{H}_{2} \mathrm{~S} \simeq 100$ at $1,400^{\circ} \mathrm{C}$. This represents a decrease in hydrogen relative to sulphur in the solar nebula by a factor of 320 .

We conclude that it is indeed possible for the earth to have accreted sulphur more efficiently than $\mathrm{Na}, \mathrm{K}, \mathrm{Mn}, \mathrm{F}$ and many other volatile elements shown in Fig. 1. However, the conditions required are quite restrictive and may not be favoured by many of those who have previously supported the view that sulphur is the principal light element in the core. The material from which most of the earth was formed must have been subjected to sustained high temperatures (exceeding $900^{\circ} \mathrm{C}$ ) in an environment in which sulphur was concentrated relative to hydrogen compared to the solar nebula by factors of 100-200. A fractionation of this kind could hardly be accomplished in the gas phase. It would appear to require an initially cold $\left(<0^{\circ} \mathrm{C}\right)$ solar nebula in which the dust particles consisted of an oxidized, volatile rich condensate somewhat similar to $\mathrm{C} 1$ chondritic material in which sulphur was fully condensed. The dust particles then became strongly concentrated relatively to gas by sedimentation, possibly combined with coagulation. The earth formed by high-temperature processing of this dust-enriched portion of the nebula. It should be noted that the degree of enrichment of primordial dust is such that this solid material constituted over 40 percent of the total mass of the system, the remainder consisting of gases, mainly $\mathrm{H}_{2}, \mathrm{He}, \mathrm{NH}_{3}, \mathrm{CH}_{4}, \mathrm{Ne}$ and $\mathrm{H}_{2} \mathrm{O}$. The earth is thus required to form largely from 
material of $\mathrm{Cl}$ chondrite composition, as, for example, in the models of RingwOod (1960, 1966a, b, 1975).

Before being obliged to accept these models, it is desirable to enquire into the possibility that elements other than sulphur might be present in substantial quantities in the outer core.

\section{Carbon, Silicon and Magnesium Oxide}

Other components which have been suggested by various authors to be present in the earth's outer core include carbon, silicon and magnesium oxide. The case for carbon is, however, much weaker than that for sulphur, since, in a cooling nebula, carbon condenses (as metastable hydrocarbons) at a much lower temperature than sulphur (ANDERS, 1971). Even if some carbon accreted in this form, most of it would react with $\mathrm{FeO}$ under transient or sustained high temperatures during accretion to form gaseous $\mathrm{CO}$ which would be lost to the atmosphere (RINGWOOD, 1960, 1966a, b). It has not been possible to devise mechanisms whereby large amounts of carbon can be trapped within the earth during accretion, finally entering the core, whilst many elements possessing much lower volatilities (e.g., alkalis, Mn, Zn, $\mathrm{Cl}, \mathrm{Pb}$ ) have become strongly depleted, owing either to partial condensation or to loss by volatilization during accretion. It is possible, however, that small amounts (e.g., 1\%) of carbon may have been trapped and have later entered the core, as, for example in the accretion model of RinGwOod (1966b).

The presence of any substantial amount of nitrogen in the earth's core can be disregarded for reasons similar to those applying to carbon.

RiNGWOOD (1958, 1959) and MACDONALD and KNOPOFF (1958) suggested that elemental silicon might be an important component of the core. However, in order to incorporate silicon in the metal, which segregated from a mantle containing FeO, Ringwood (1959, 1960, 1966b) was obliged to postulate a very specific model for the accretion of the earth and the subsequent core-formation process, which was required to occur under conditions leading to gross disequilibrium between core and mantle. Difficulties associated with this model have been pointed out by Grossman (1972) and by BRETT (1971, 1976). In my view, these difficulties can be overcome, but the resulting model is somewhat contrived, thereby lessening its plausibility.

BRETT (1971) and KuSKOV and KhITAROV (1974) proposed that at high pressures and temperatures the equilibrium:

$$
\mathrm{SiO}_{2}(\text { stishovite })+2 \mathrm{Fe}=2 \mathrm{FeO}+\mathrm{Si}
$$

proceeds to the right, so that silicon might enter into solution in the earth's core under equilibrium conditions. There are at least two serious objections to this proposal:

(1) The equilibrium may proceed to the right only under $\mathrm{P}, \mathrm{T}$ conditions which can be attained in the deep mantle (Kuskov and Khitarov, 1974). In order to introduce even 10 weight percent of silicon into the core via this reaction, about 40 weight percent of $\mathrm{FeO}$ is required in the lower mantle below $1,000 \mathrm{~km}$. The physical properties of the lower mantle limit the $\mathrm{FeO}$ content to about 10 weight percent (RINGWOOD, 1975).

(2) The calculations of KusKov and KHITAROV (1974) are based upon the assumption that stishovite occurs as a separate phase in the lower mantle. However, the high pressure experiments of LiU $(1975,1976)$ show that the principal mineral assemblage in the lower mantle probably consists of $\mathrm{MgSiO}_{3}$ perovskite + $\mathrm{MgO}$. Stishovite does not occur as a separate phase. The perovskite form of $\mathrm{MgSiO}_{3}$ is about 4 percent denser than an isochemical mixture of $\mathrm{MgO}$ plus stishovite. If a term incorporating an appropriate estimate for the free energy of formation of $\mathrm{MgSiO}_{3}$ perovskite is incorporated in KUSKOV and KHITAROv's calculations, the $\mathrm{P}, \mathrm{T}$ region in the lower mantle where $\mathrm{MgSiO}_{3}$ can be reduced by $2 \mathrm{Fe}^{\circ}$ to form $\mathrm{MgO}+2 \mathrm{FeO}+$ $\mathrm{Si}^{\circ}$ is greatly reduced.

A LDER (1966) has suggested that the core contains about 10 percent of magnesium oxide in solution and that this component is responsible for the lower density of the core, as compared to pure liquid iron. His estimate is obtained from solubility theory calculations based upon the Van der Waals theory of liquids and solutions. ITo (1976) also proposed that the outer core has dissolved a substantial amount of $(\mathrm{Mg}, \mathrm{Fe}) \mathrm{O}$, equivalent in composition to that of the oxide phase (MO) present in the lower mantle. $\mathrm{He}$ does not distinguish between $\mathrm{MgO}$ and $\mathrm{FeO}$ in his discussion, but $\mathrm{MgO}$ is regarded as the major component. ITO attempts to model the terrestrial planets in terms of this hypothesis but does not advance any significant arguments beyond those proposed by ALDER for believing 
that $\mathrm{MgO}$ would indeed be soluble in molten iron at core pressures.

It is not possible to assess the significance of ALDER's hypothesis since empirical data on several key physical quantities needed for his calculations were not available. In the absence of these data, a very large uncertainty must be placed upon ALDER's estimate of the solubility of $\mathrm{MgO}$ in molten Fe. Whilst the hypothesis cannot be evaluated in an absolute sense, its plausibility can be considered in relation to that of a closely analogous hypothesis. In the following section, we consider evidence relating to the solubility of $\mathrm{FeO}$ in molten iron and suggest that $\mathrm{FeO}$ may be an important "light" component in the core. How does the MgO hypothesis compare?

The significant observational fact is that $\mathrm{FeO}$ displays a substantial degree of solubility in molten iron, and that this solubility increases sharply with increasing temperature (Fig. 2). Although the relevant systems have been well studied, there is, as yet, no evidence which suggests that $\mathrm{MgO}$ possesses a solubility comparable to that of $\mathrm{FeO}$ under similar conditions. Indeed, electropositive elements such as $\mathrm{Al}, \mathrm{Si}$ and $\mathrm{Mn}$ possessing very high chemical affinities for oxygen are used as additives for the purpose of deoxidizing steels. The solubilities of the oxides of these elements in molten iron are thus much smaller than that of FeO. Magnesium has a higher affinity for oxygen than any of these elements and is a more efficient deoxidizer (BoDSWORTH, 1963). (It is not used commercially because of the small solubility of ele-

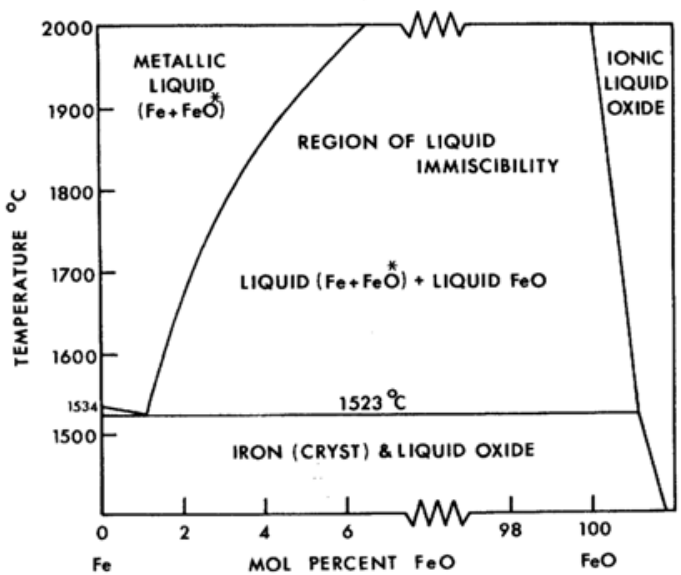

Fig. 2. Experimentally determined phase equilibria in the system $\mathrm{Fe}-\mathrm{FeO}$ at 1 atmosphere in the temperature interval 1,500-2,000 ${ }^{\circ} \mathrm{C} . \quad$ (After Distin et al., 1971). mental magnesium in molten iron.) There can be no reasonable doubt, therefore, that $\mathrm{MgO}$ is much less soluble in molten iron than $\mathrm{FeO}$.

\section{IRON OXIDE IN THE CORE}

BIRCH (1952) suggested the possibility of oxygen (among several other elements) being present in the core. RingwOOD (1966a) argued against this on the grounds that oxygen would form interstitial solutions and would not therefore reduce the density of iron as required. However, in section 1 , we noted that this objection is probably not valid under the very high pressures prevailing in the core.

DUBRETSEV and PAN'KOV (1972) pointed out that at high pressures, ferrous oxide would be expected to transform to the metallic state and made an estimate of the density of metallic $\mathrm{FeO}$. They suggested that the density of the outer core could be explained if it consisted of a mixture of about 60 percent liquid metallic $\mathrm{FeO}$ plus 40 percent of nickel iron. A related suggestion was put forward by Bullen (1973a, b) who proposed that the outer core consists of iron sub-oxide, $\mathrm{Fe}_{2} \mathrm{O}$. These suggestions derived from efforts to interpret the density distributions within the earth and terrestrial planets and chemical evidence bearing on these hypotheses was largely ignored. It appeares to the author that these hypotheses are deserving of further exploration in the light of chemical evidence not considered by the above authors.

(a) Solubility of $\mathrm{FeO}$ in molten iron at low pressure We wish to investigate the possibility that the outer core consists of a solution of $\mathrm{FeO}$ in molten metallic iron-nickel. Near the liquidus at atmospheric pressure, the solubility of molten $\mathrm{FeO}$ in molten iron is very small, in the vicinity of $1 \mathrm{~mol}$. percent (Fig. 2). This behaviour is not, however, shared by several other transition metals. For example, in the systems $\mathrm{Ti}-\mathrm{TiO}, \mathrm{V}-\mathrm{VO}, \mathrm{Nb}-\mathrm{NbO}, \mathrm{Zr}-\mathrm{ZrO}_{2}$ and $\mathrm{Y}-\mathrm{Y}_{2} \mathrm{O}_{3}$, extensive or complete miscibility occurs between metal and oxide in the oxide in the liquid state (HANSEN and ANDERKO, 1958; ELLIOT, 1965).

The solubility of molten $\mathrm{FeO}$ in molten $\mathrm{Fe}$ increases rapidly with increasing temperatures in the range $1,500-2,000^{\circ} \mathrm{C}$ (HANSEN and Anderko, 1958; Distin et al., 1971). Experimentally determined phase relationships in the system $\mathrm{Fe}-\mathrm{FeO}$ are shown in Fig. 2. It is 
seen that the solubility of $\mathrm{FeO}$ in molten iron reaches nearly $7 \mathrm{~mol}$. percent at $2,000^{\circ} \mathrm{C}$. The solubility of oxygen in molten iron between 1,500 and $2,000^{\circ} \mathrm{C}$ is accurately described by the following relationship (DISTIN et al., 1971).

$$
\log _{10}(\text { wt.\%O })=\frac{-6380}{\mathrm{~T}\left({ }^{\circ} \mathrm{K}\right)}+2.765
$$

This relationship has been used to calculate the solubility of $\mathrm{FeO}$ in iron at higher temperatures outside the experimental range (Fig. 3). The solubility of $\mathrm{Fe}$ in $\mathrm{FeO}$ in Fig. 3 has likewise been calculated from the experimental measurements of Distin et al. (1971). Approximately $40 \mathrm{~mol}$. percent of $\mathrm{FeO}$ dissolves in liquid iron at $3,000^{\circ} \mathrm{C}$ whilst at $3,500^{\circ} \mathrm{C}$ the proportion of dissolved $\mathrm{FeO}$ is in the vicinity of $70 \mathrm{~mol}$. percent. The temperature at the base of the mantle probably exceeds, $3,000^{\circ} \mathrm{C}$ (J ACOBS, 1975; HigGins and KENNEDY, 1971) so that extensive solubility of $\mathrm{FeO}$ in iron should be possible in the core. Moreover, we will find below that the solubility of $\mathrm{FeO}$ in $\mathrm{Fe}$ is greatly augmented by the effects of high pressure.

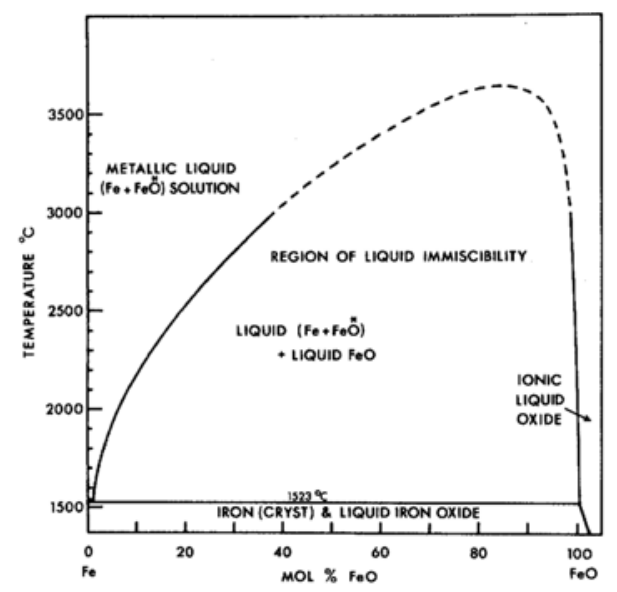

Fig. 3. Calculated phase diagram for the system $\mathrm{Fe}$ $\mathrm{FeO}$ at $1 \mathrm{~atm}$. based upon experimental measurement of solubility relationships between 1,500 and $2,000^{\circ} \mathrm{C}$ (Fig. 2) at 1 atmosphere.

(b) Effect of high pressures on $\mathrm{FeO}$ At low pressures, ferrous oxide is an essentially ionic solid, possessing the rock-salt structure. As pressure is increased and the $\mathrm{Fe}^{2+}$ and the $\mathrm{O}^{2-}$ ions are forced closer together, overlap of the outer electronic orbitals occurs, leading to an increasing covalent character of the chemical bond. With further increase in pressure, de- localization of electrons will occur, leading to a partially metallic bond. At this stage, $\mathrm{FeO}$ could be regarded as an intermetallic semiconductor, comparable to FeS. Ultimately, at very high pressure, overlap between the valence band and the conduction band occurs, and the metallic state is reached. Non-metal to metal transformations are usually but not necessarily accompanied by one or more first order polymorphic transitions and the accompanying density changes may be quite large, e.g., 10 to 40 percent in the cases of $\mathrm{C}, \mathrm{Si}, \mathrm{Ge}, \mathrm{Sn}, \mathrm{P}, \mathrm{S}, \mathrm{I}$. Many oxides, e.g., $\mathrm{V}_{2} \mathrm{O}_{3}, \mathrm{Ti}_{2} \mathrm{O}_{3}, \mathrm{Fe}_{3} \mathrm{O}_{4}, \mathrm{NbO}_{2}$, $\mathrm{TiO}, \mathrm{MnO}_{2}, \mathrm{MoO}_{2}, \mathrm{IrO}_{2}$ and $\mathrm{WO}_{2}$ display metallic conductivity at atmospheric pressure in limited temperature ranges (ADLER, 1969).

An approximate estimate of the density of the metallic or semi-metallic form of $\mathrm{FeO}$ can be obtained from bond-length considerations. In pure, stoichiometric wüstite, the $\mathrm{Fe}^{2+}-\mathrm{O}^{2+}$ bond length is $2.162 \AA$ (KATSURA et al., 1967), whereas the covalent-metallic Fe-O distance is $2.01 \AA$ (Evans, 1966). Thus, the metallic form of $\mathrm{FeO}$ is expected to be denser than the ionic form in the ratio $\left(\frac{2.162}{2.01}\right)^{3}$, assuming no change in crystal structure. This would imply a density of $7.34 \mathrm{~g} / \mathrm{cm}^{3}$ for the metallic form of $\mathrm{FeO}$ as compared to 5.91 for pure stoichiometric wüstite.

At very high pressures, under shock leading, $\mathrm{Fe}_{2} \mathrm{O}_{3}\left(\rho_{0}=5.27 \mathrm{~g} / \mathrm{cm}^{3}\right)$ and $\mathrm{Fe}_{3} \mathrm{O}_{4}\left(\rho_{0}=5.20\right.$ $\mathrm{g} / \mathrm{cm}^{3}$ ) transform into high pressure phases possessing zero-pressure densities estimated as 6.05 $\mathrm{g} / \mathrm{cm}^{3}$ and $6.40 \mathrm{~g} / \mathrm{cm}^{3}$, respectively (DAVIES and GAFFNEY, 1973). These dense phases may well be semi-metallic or metallic. It seems quite likely that $\mathrm{FeO}$ would be shocked into a similar dense state at comparable pressures. If the $\mathrm{Fe}$ and $\mathrm{O}$ atoms were packed as densely as in the high-pressure forms of $\mathrm{Fe}_{2} \mathrm{O}_{3}$ and $\mathrm{Fe}_{3} \mathrm{O}_{4}$, the density of high-pressure $\mathrm{FeO}$ would be $7.1 \mathrm{~g} / \mathrm{cm}^{3}$, in good agreement with our previous estimate for the density of metallic $\mathrm{FeO}$.

A large number of non-metallic elements including $\mathrm{B}, \mathrm{C}, \mathrm{N}, \mathrm{Si}, \mathrm{P}$ and $\mathrm{S}$ form solid solutions or intermetallic compounds with metallic iron. The structures of these solid solutions and compounds are very close-packed and the chemical bonding is essentially metallic. This group of elements may thus be regarded as "metallic" components of their respective systems. In this state, their partial molar volumes are much smaller than in their normal nonmetallic states. There is little doubt that solutions of oxygen in metallic iron (equivalent to 
solutions of $\mathrm{FeO}$ ) would possess analogous metallic properties. Thus, in discussing the solubility of $\mathrm{FeO}$ in metallic iron, it is both convenient and realistic to consider the $\mathrm{FeO}$ to be present as a hypothetical, dense metallic component, identical to that which is ultimately produced by the action of very high pressures upon wüstite. In the following discussion, we will denote this metallic form as $\mathrm{FeO}^{*}$ and the normal form as $\mathrm{FeO}$.

(c) Effect of pressure on the solubility of $\mathrm{FeO}$ in molten iron Consider now, the solubility of pure liquid $\mathrm{FeO}^{*}$ in liquid iron (Figs. 2 and 3). At temperatures above $1,523^{\circ} \mathrm{C}$, increasing amounts of $\mathrm{FeO}^{*}$ enter into solution in the metal. At a given absolute temperature $\mathrm{T}$, the free energy difference, $\Delta G^{0}$, between normal non-metallic $\mathrm{FeO}$ and the hypothetical metallic form of $\mathrm{FeO}^{*}$ is given by (e.g., R INGWOOD, 1975, p. 361).

$$
\Delta G^{0}=R T \ell \frac{a_{1}}{a_{2}}
$$

where $\mathrm{a}_{1}=$ activity of $\mathrm{FeO}$ in the non-metallic phase referred to pure $\mathrm{FeO}$ as the standard state, and $\mathrm{a}_{2}=$ activity of $\mathrm{FeO}^{*}$ in the metallic phase referred to pure $\mathrm{FeO}^{*}$ as the standard state. We assume that the metallic solution of $\mathrm{FeO}^{*}$ in $\mathrm{Fe}$ behaves ideally, i.e., $\mathrm{a}_{2}$ is equal to $\mathrm{N}_{2}$ where $\mathrm{N}_{2}$ is the mole fraction of $\mathrm{FeO}^{*}$ in the metallic solution as obtained from Figs. 2 and 3. This assumption is probably not unreasonable at the high temperatures $\left(1,500-3,500^{\circ} \mathrm{C}\right)$ under consideration. The experimentally measured solubilities of $\mathrm{FeO}^{*}$ in $\mathrm{Fe}$ shown in Fig. 3 refer to conditions of saturation with essentially pure $\mathrm{FeO}$, i.e., $\mathrm{a}_{\mathrm{FeO}}=\mathrm{a}_{1}=1$, since the solubility of iron in liquid $\mathrm{FeO}$ is comparatively very small. Thus, we have

$$
\Delta \mathrm{G}^{0}=-\mathrm{RT} \ln \mathrm{N}_{2}
$$

with $\mathrm{N}_{2}$ given by Figs. 2 and 3 .

It is of interest to calculate the pressure at which pure non-metallic liquid $\mathrm{FeO}$ would transform to metallic liquid $\mathrm{FeO}^{*}$ at an appropriate temperature, e.g., $2,500^{\circ} \mathrm{C}$. The free energy difference between the two states is found to be 37,700 joules/mol from equation II. This is approximately equal to $\mathrm{P} \Delta \mathrm{v}$, where $\Delta \mathrm{v}$ is the difference in molar volumes between liquid $\mathrm{FeO}$ and $\mathrm{FeO}^{*}$. Taking this to be the same as the molar volume difference previously estimated between solid $\mathrm{FeO}$ and $\mathrm{FeO}^{*}$ (i.e., $\Delta \mathrm{v}=-2.38$ cc), we calculate $P$, the pressure needed to transform liquid $\mathrm{FeO}$ into the metallic state FeO* at $2,500^{\circ} \mathrm{C}$ to be 158,000 bars. This is quite small compared to the pressure at the base of the mantle $\left(1.4 \times 10^{6}\right.$ bars).

The effect of high pressure upon the phase diagram Fe-FeO (Figs. 2, 3) will be to depress and reduce the extent of the liquid immiscibility field between $(\mathrm{Fe}-\mathrm{FeO}) *$ metal solution and (FeO-Fe) oxide solution. Calculations along the lines given above indicate that at pressures above about $300 \mathrm{~kb}$, complete miscibility will occur between $\mathrm{Fe}^{0}$ and $\mathrm{FeO}$ at the solidus. The resultant phase diagram would be qualitatively similar to that displayed by the analogous system Fe-FeS (HANSEN and ANDERKo, 1958).

The result obtained above shows that the high pressures reached in the earth's mantle should cause a large increase in the solubility of $\mathrm{FeO}$ in molten iron. We can estimate the significance of this effect by considering the distribution of $\mathrm{FeO}$ between the mineral assemblage prevailing in the lower mantle and the $\mathrm{Fe}-\mathrm{FeO}$ * metallic solution in the core. Recent studies of the constitution of the lower mantle based upon high pressure experimentation have led to the conclusion that the principal mineral assemblage in this region consists of $(\mathrm{Mg}, \mathrm{Fe}) \mathrm{SiO}_{3}$ (perovskite) $+(\mathrm{Mg}, \mathrm{Fe}) \mathrm{O}$ (rocksalt) solid solutions (LiU, 1974, 1975, 1976; RINGWOOD, 1975). The overall $\mathrm{MgO} /(\mathrm{MgO}+\mathrm{FeO})$ molar ratio for the lower mantle is close to 0.88 (RINGWOoD, 1975) and we will assume that the $\mathrm{MgO} / \mathrm{FeO}$ ratio of rocksalt solid solution is the same as that of the $(\mathrm{Mg}, \mathrm{Fe}) \mathrm{SiO}_{3}$ perovskite. Assuming also that the $\mathrm{MgO}-\mathrm{FeO}$ solution behaves ideally (a reasonable assumption at $\mathrm{T}>2,000^{\circ} \mathrm{C}$ ) and ignoring a small term ${ }^{1}$ arising from the entropy of fusion of $\mathrm{FeO}$, we take the activity of $\mathrm{FeO}$ in the lower mantle (referred to pure liquid $\mathrm{FeO}$ as the standard state) to be the same as its mol. fraction, $N_{1}$ and equal to 0.12 . The distribution of $\mathrm{FeO}$ between the oxide and metallic solution as a function of pressure $P$ is given by:

$$
\Delta G^{0}+P \Delta v=R T \ln \frac{a_{1}}{a_{2}}=R T \ln \frac{N_{1}}{N_{2}}
$$

In this expression, $\Delta G^{0}$ is the zero pressure free energy change in transforming pure $\mathrm{FeO}$ to

\footnotetext{
1 Inclusion of this term would cause a small reduction in the pressure required for a given amount of $\mathrm{FeO}$ * to enter the core, as given in subsequent calculations.
} 
metallic $\mathrm{FeO}^{*}$ and is given by eq. I, whilst $\Delta \mathrm{v}$ is the molar volume difference between $\mathrm{FeO}$ and $\mathrm{FeO} *\left(\mathrm{~V}_{\mathrm{FeO}} *-\mathrm{V}_{\mathrm{FeO}}\right)$ and is negative. Previously we estimated $\Delta \mathrm{v}$ to be about -2.4 $\mathrm{cc} / \mathrm{mol}$ for crystalline $\mathrm{FeO}^{*}$ and $\mathrm{FeO}$. A comparable difference probably applies in the liquid state. $\quad \mathrm{N}_{1}$ is given by the $\mathrm{FeO} /(\mathrm{FeO}+\mathrm{MgO})$ ratio of the oxide phase in the lower mantle. It is thus possible to solve equation III for $\mathrm{N}_{2}$, the solubility of $\mathrm{FeO}^{*}$ in $\mathrm{Fe}$ as a function of pressure at temperature, T. Results are given in Table 3.

Table 3. Calculated solubilities of $\mathrm{FeO}$ in molten iron in equilibrium with $\left(\mathrm{Mg}_{0.88} \mathrm{Fe}_{0.12}\right) \mathrm{O}$ at $2,500^{\circ} \mathrm{C}$ as a function of pressure $P$.

\begin{tabular}{cc}
\hline P bars & $\begin{array}{c}\text { Solubility } \\
\text { Mol. percent } \mathrm{FeO}\end{array}$ \\
\hline 0 & 2 \\
50,000 & 4 \\
100,000 & 7 \\
150,000 & 12 \\
200,000 & 18 \\
250,000 & 31 \\
300,000 & 52 \\
350,000 & 87 \\
\hline
\end{tabular}

We see that at a temperature of $2,500^{\circ} \mathrm{C}$, the metal phase in equilibrium with the lower mantle mineral assemblage would contain 52 mol. percent $\mathrm{FeO}$ at a pressure of $300 \mathrm{~kb}$, and that solubility increases very rapidly with pressure in the interval $300-350 \mathrm{~kb}$. Figures 2 and 3 in conjunction with equation III imply that the temprature gradient $\mathrm{dP} / \mathrm{dT}$ for this transition is negative. Thus, at temperatures higher than $2,500^{\circ} \mathrm{C}$, the pressures required for corresponding degrees of solubility of $\mathrm{FeO}^{*}$ in $\mathrm{Fe}^{0}$ are reduced (Figs. 2, 3; Equation III).

Although the above calculations are necessarily oversimplified, their "margin of safety" is rather broad. It is predicted that the liquid metal phase in equilibrium with the minerals of the earth's lower mantle would contain large amounts of $\mathrm{FeO}$ at pressures as low as $300 \mathrm{~kb}$ and temperatures as low as $2,500^{\circ} \mathrm{C}$. The pressure at the base of the mantle is 1.4 megabar and at the centre of the earth, $3.6 \mathrm{mb}$. Temperatures within the core almost certainly exceed $2,500^{\circ} \mathrm{C}$.

The principal assumptions made in the calculations relate to the activities of $\mathrm{FeO}$ and $\mathrm{FeO}^{*}$ in mantle and core, and the volume change between $\mathrm{FeO}$ and $\mathrm{FeO}^{*}$. The activity coefficients $(\gamma=\mathrm{a} / \mathrm{N})$ enter as logarithms into equa- tion III which is used to calculate the pressuresolubility relationship. In order to cast doubt upon our inference that $\mathrm{FeO}$ is likely to be an important constituent of the earth's core, it would be necessary to introduce activity coefficients for $\mathrm{FeO}$ and $\mathrm{FeO}^{*}$ on the order of $10^{4}$. By comparison with the properties of solutions of molten iron with related intermetallic compounds such as $\mathrm{FeS}, \mathrm{Fe}_{3} \mathrm{C}, \mathrm{Fe}_{4} \mathrm{~N}, \mathrm{FeSi}$ and $\mathrm{Fe}_{3} \mathrm{P}$ (KUBACHEWSKI and EVANS, 1958), this seems highly improbable. Likewise, if the lower mantle contained a high-pressure modification of $(\mathrm{Mg}, \mathrm{Fe})_{2} \mathrm{SiO}_{4}$ as a major phase rather than $(\mathrm{Mg}, \mathrm{Fe}) \mathrm{O}$, any reasonable estimate of the activity of $\mathrm{FeO}$ in the $\mathrm{HP}(\mathrm{Mg}, \mathrm{Fe})_{2} \mathrm{SiO}_{4}$ phase would not be small enough to negate the basic conclusion reached above.

Another uncertainty in our discussion concerns the magnitude of $\Delta \mathbf{v}$ in relation to the suggestion (FYFE, 1960) that $\mathrm{Fe}^{2+}$ might undergo a transition in the lower mantle from the high-spin to the low-spin state. STRENS (1969) has estimated the transition pressure as about $660 \mathrm{~kb}$ at $2,500^{\circ} \mathrm{C}$. The transition would be accompanied by a substantial reduction in the volume of the $\mathrm{FeO}$ component. An estimate of the ionic radius of $\mathrm{Fe}^{2+}$ (LS) by SHANNON and PREWITT (1969) implies a molar volume for $\mathrm{FeO}$ (LS) of $9.90 \mathrm{~cm}^{3}$, only slightly larger than that of $\mathrm{FeO}^{*}\left(9.79 \mathrm{~cm}^{3}\right)$.

However, estimates of $\mathrm{Fe}(\mathrm{LS})-\mathrm{O}$ bond lengths by Shannon and PrewitT (1969) and STRENS (1969) are based upon highly covalent compounds such as ferrocyanides and sulphides. Tossell (1976) points out that the ionic radius of divalent iron in fluorides contracts by only $0.03 \AA$ in changing from high-spin to low-spin states (as compared to $0.16 \AA$ obtained by ShanNon and PrewitT). A. F. ReID (pers. com.) has concluded from a study of the HS $\rightarrow$ LS transition in cobalt oxide that the change in $\mathrm{HS} \rightarrow \mathrm{LS}$ radius estimated for $\mathrm{Fe}^{2+}$ by SHANNON and PrewitT is much too large.

It seems that both the transition pressure and volume of $\mathrm{FeO}$ (LS) are very poorly known. The high-spin to low-spin transition in $\mathrm{Fe}^{2+}$ may, or may not occur within the mantle. There is, as yet, no means of quantifying the possible role of low-spin iron in the lower mantle. If we ignore this possible role, then we are justified in concluding that it is highly probable that $\mathrm{FeO}$ is a major component of the core. This conclusion would also hold in the event of a $\mathrm{HS} \rightarrow \mathrm{LS}$ transition in $\mathrm{Fe}^{2+}$ providing that the volume of $\mathrm{FeO}$ (LS) was appreciably higher than 
that of $\mathrm{FeO}^{*}$, as indicated by studies of the transition in iron fluoride and cobalt oxide.

If, on the other hand, the ionic radius of $\mathrm{Fe}^{2+}$ (LS) is as small or smaller than the value of $0.61 \AA$ suggested by SHANNON and PrewitT (1969), then its solubility in magnesium oxide and silicates $\left(\mathrm{Mg}^{2+}-0.72 \AA\right)$ in the lower mantle may be severely restricted since the size difference exceeds the 15 percent Goldschmidt tolerance factor* normally required for extensive solid solution. In this case, much of the $\mathrm{FeO}$ in the lower mantle may be obliged to form a separate phase with unit thermodynamic activity. The solubility of this phase in liquid iron will then be governed by the $(\mathrm{Fe}-\mathrm{FeO})$ phase diagram, Fig. 3, and will be large above $2,500^{\circ} \mathrm{C}$.

In the above discussion, we have assumed that the transition from normal $\mathrm{FeO}$ to the metallic-covalent form $\left(\mathrm{FeO}^{*}\right)$ is first order. This assumption was made in order to simplify the semi-quantitative calculations on the effect of pressure upon solubility of $\mathrm{FeO}^{*}$ in iron. It is equally possible that the transition is of second or higher order, as is implicit in the broken line of the phase boundary shown in Fig. 3. Providing that our estimate of ultimate density of the metallic form of $\mathrm{FeO}^{*}$ is approximately correct, the basic conclusions regarding the effect of pressure on solubility of $\mathrm{FeO}^{*}$ in $\mathrm{Fe}$ will not be changed.

(d) Possibility of disproportionation of $\mathrm{FeO}$ in the lower mantle When wüstite is cooled at atmospheric pressure, it disproportionates at $560^{\circ} \mathrm{C}$ into magnetite plus metallic iron:

$$
4 \mathrm{FeO}=\mathrm{Fe}_{3} \mathrm{O}_{4}+\alpha \mathrm{Fe}, \Delta \mathrm{v}=+3.0 \mathrm{~cm}^{3}
$$

Because the disproportionation is accompanied by an increase in volume, the effect of pressure favours the stability of $\mathrm{FeO}$. However, under shock loading at very high pressure $(\leq 600$ $\mathrm{kb})$, magnetite $\left(\rho_{0}=5.20 \mathrm{~g} / \mathrm{cm}^{3}\right)$ transforms to a very dense phase possessing an estimated zero pressure density of $6.40 \mathrm{~g} / \mathrm{cm}^{3}$ (DAVIES and GAFFNEY, 1973). It is possible that this phase may be identical to a high pressure polymorph of $\mathrm{Fe}_{3} \mathrm{O}_{4}$ discovered by $\mathrm{MAO}$ et al. (1974) at about $250 \mathrm{~kb}$ using a diamond pressure cell. Moreover, $\alpha \mathrm{Fe}$ transforms to the denser $\epsilon$ polymorph at about $130 \mathrm{~kb}\left(15^{\circ} \mathrm{C}\right)$. Thus, at pressures corresponding to those in the deep mantle, the reaction

$$
4 \mathrm{FeO}=\mathrm{Fe}_{3} \mathrm{O}_{4} \text { (h.p.p.) }+\epsilon \mathrm{Fe}, \Delta \mathrm{v}=-5.8 \mathrm{~cm}^{3}
$$

is accompanied by a large decrease in volume, implying that the disproportionation reaction is favoured by pressure. The free energy of this reaction will be dominated by the P. $\Delta \mathrm{v}$ term at mantle pressures. If the pressure required for the disproportionation reaction is smaller than that required to transform $\mathrm{FeO}$ to the metallic state $\left(\mathrm{FeO}^{*}\right)$, then the disproportionation reaction will intervene (MAO, 1974). Under these circumstances, the high pressure polymorph of $\mathrm{Fe}_{3} \mathrm{O}_{4}$ (hpp) may be formed as a separate phase in the lower mantle according to the following simplified equilibrium:

$\mathrm{MgFeSi}_{2} \mathrm{O}_{6}$ (perovskite) $+\mathrm{MgO}=$ $2 \mathrm{MgSiO}_{3}$ (perov.) $+1 / 4 \mathrm{Fe}_{3} \mathrm{O}_{4}(\mathrm{hpp})+1 / 4 \mathrm{Fe}(\epsilon)$

(In a more realistic case, some $\mathrm{FeO}$ would remain in solid solution with $\mathrm{MgO}$ in the perovskite and rocksalt phases because of stabilization caused by the entropy of mixing $\mathrm{Mg}^{2+}$ and $\mathrm{Fe}^{2+}$.)

We have already suggested that the ironoxygen packing density of $\mathrm{Fe}_{3} \mathrm{O}_{4}$ (hpp) may be similar to that of $\mathrm{FeO}^{*}$, implying that oxygen possesses a similar partial molar volume in both states. Thus, the effect of pressure upon solubility of h.p.p. $\mathrm{Fe}_{3} \mathrm{O}_{4}$ in molten $\mathrm{Fe}$ may not be large. However, the effect of temperature on solubility of $\mathrm{Fe}_{3} \mathrm{O}_{4}$ (hpp) in molten Fe will be similar to that of $\mathrm{FeO}$ (Figs. 2 and 3) since the stoichiometry of the discrete iron-oxide phase is not an important factor. In both cases, we are considering, ultimately, the solubility of oxygen in molten iron. Indeed, this is the form in which metallurgists usually express their phase diagram.

We conclude that if much of the $\mathrm{FeO}$ in the deep mantle (initially present in rocksalt and perovskite phases) ultimately disproportionates to form $\mathrm{Fe}_{3} \mathrm{O}_{4}$ (hpp) plus $\epsilon \mathrm{Fe}$ under subsolidus conditions, then the iron oxide phase will dissolve extensively in molten iron when temperature exceeds about $2,500-3,000^{\circ} \mathrm{C}$ (Fig. 3), so that " $\mathrm{FeO}$ " is still expected to be an important component of the core.

Under shock loading, hematite $\left(\rho_{0}=5.27\right.$ $\mathrm{g} / \mathrm{cm}^{3}$ ) transforms to a much denser form with an estimated zero pressure density of $6.05 \mathrm{~g} / \mathrm{cm}^{3}$ (D AVIES and GafFNEY, 1973). Thus, we might also consider the disproportionation of $\mathrm{FeO}$ into $\mathrm{Fe}_{2} \mathrm{O}_{3}(\mathrm{hpp})+\mathrm{Fe}(\epsilon)$ in the deep mantle 
(MAO, 1974).

$$
3 \mathrm{FeO}=\mathrm{Fe}_{2} \mathrm{O}_{3}(\mathrm{hpp})+\mathrm{Fe}(\epsilon), \quad \Delta \mathrm{v}=-3.4 \mathrm{~cm}^{3}
$$

The overall consequences would be similar to the case previously considered in which $\mathrm{FeO}$ disproportionated into $\mathrm{Fe}_{3} \mathrm{O}_{4}$ (hpp) $+\mathrm{Fe}(\epsilon)$. However, because of the higher density of the latter assemblage, it is probably more relevant to considerations of lower mantle mineralogy.

(e) $\mathrm{FeO}$ content of the core

The amount of $\mathrm{FeO}^{*}$ in the core needed to reduce its density by about 8 percent (McQUEEN and MARSH, 1966) as compared to pure iron is difficult to estimate. Based upon our estimate of the density of $\mathrm{FeO}^{*}$ at zero pressure, about 70 weight percent of $\mathrm{FeO}^{*}$ would be required. However, this is almost certainly too high. The high pressure form of $\mathrm{FeO}^{*}$ would probably possess a higher bulk modulus than metallic iron, as is displayed by the corresponding carbides and by the high pressure forms of $\mathrm{Fe}_{3} \mathrm{O}_{4}$ and $\mathrm{Fe}_{2} \mathrm{O}_{3}$. Thus, whilst the bulk modulus of iron is $1.68 \mathrm{Mbar}$, the bulk moduli of the high pressure phases of $\mathrm{Fe}_{3} \mathrm{O}_{4}$ and $\mathrm{Fe}_{2} \mathrm{O}_{3}$ calculated at zero pressure are estimated to be 3.65 and $3.51 \mathrm{Mbar}$, respectively (DAVIES and GAFFNEY, 1973). Therefore, the density of $\mathrm{FeO}^{*}$ will probably not increase with pressure nearly as rapidly as pure Fe. Moreover, the increasing tendency of oxygen atoms to form substitutional solutions rather than interstitial solutions at high pressure would also decrease the amount of $\mathrm{FeO}^{*}$ needed to reduce the density of pure iron by 8 percent.

The best estimate is probably derived by comparing the density of iron oxide obtained under very high pressures by shock wave methods with the observed density of the outer core. We approximate the density of $\mathrm{FeO}^{*}$ by assuming that it is similar to that of an isochemical mixture of magnetite $\left(\mathrm{Fe}_{3} \mathrm{O}_{4}\right)$ plus metallic iron. Using the Hugoniot data tabulated by BIRCH (1966), the density of a mixture of $\mathrm{Fe}_{3} \mathrm{O}_{4}+\mathrm{Fe}^{0}$ at $1.4 \mathrm{Mbar}$ is $8.57 \mathrm{~g} / \mathrm{cm}^{3}$, compared to the density of the outer core at the same pressure, which is $9.98 \mathrm{~g} / \mathrm{cm}^{3}$ (DzwIEWONSKI et al., 1975). The density of iron on the Hugoniot at this pressure is $11.3 \mathrm{~g} / \mathrm{cm}^{3}$. Since the Hugoniot temperatures at this pressure are probably similar to temperatures in the core, we disregard the effect of temperature upon density differentials. It is, however, necessary to correct the Hugoniot density downwards by 4 percent to allow for the volume change on melting. The density of pure molten iron at $1.4 \mathrm{Mbar}$ is thus taken as $10.85 \mathrm{~g} / \mathrm{cm}^{3}$. From these figures, we find that the core would contain 44 weight percent of $\mathrm{FeO}$, equivalent to 10 weight percent of oxygen.

\section{INCORPORATION OF IRON OXIDE INTO THE EARTH}

The incorporation of $\mathrm{FeO}$ into the earth under conditions wherein most of the primordial complements of many volatile elements (e.g., $\mathrm{Na}, \mathrm{K}, \mathrm{Cl}, \mathrm{Zn}$ ) were excluded poses problems analogous to those encountered in the case of sulphur (section 2). Equilibrium calculations (Grossman, 1972) show that substantial amounts of $\mathrm{FeO}$ do not enter magnesium silicates condensing from gases of solar composition until the temperature has fallen below $300^{\circ} \mathrm{C}$ (Fig. 4). However, temperatures exceeding $800^{\circ} \mathrm{C}$ are needed to volatilize sodium and potassium. It is possible in principle for oxidized iron to enter the earth by two different processes.

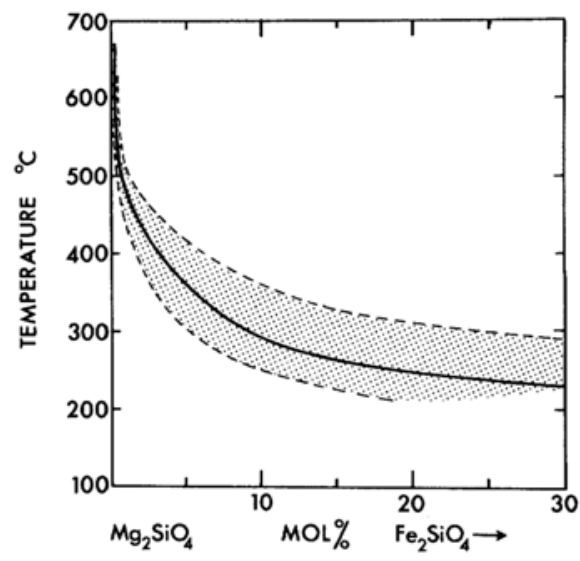

Fig. 4. Equilibrium fayalite content of olivine as a function of temperature in a partially condensed system of solar composition. Shaded area represents uncertainty limits. (Based on data of Grossman, 1972.)

(a) Decrease in $\mathrm{H}_{2} / \mathrm{H}_{2} \mathrm{O}$ ratio in region of nebula wherein earth accreted In order to condense substantial amounts of $\mathrm{FeO}$ in silicates at temperatures above $800^{\circ} \mathrm{C}$, the $\mathrm{H}_{2} / \mathrm{H}_{2} \mathrm{O}$ ratio must be greatly reduced. The redox state of iron and the composition of coexisting silicates are governed by the simplified equilibrium (Mueller, 1964):

$$
\begin{aligned}
\mathrm{MgSiO}_{3}+\mathrm{Fe}+\mathrm{H}_{2} \mathrm{O} & =1 / 2 \mathrm{Fe}_{2} \mathrm{SiO}_{4}+1 / 2 \mathrm{Mg}_{2} \mathrm{SiO}_{4}+\mathrm{H}_{2} \\
\text { "K" } & =\mathrm{H}_{2} / \mathrm{H}_{2} \mathrm{O}
\end{aligned}
$$


Table 4. Equilibrium constants for the simplified reaction:

$\mathrm{MgSiO}_{3}+\mathrm{Fe}+\mathrm{H}_{2} \mathrm{O}=1 / 2 \mathrm{Fe}_{2} \mathrm{SiO}_{4}+1 / 2 \mathrm{Mg}_{2} \mathrm{SiO}_{4}+\mathrm{H}_{2}$ corresponding to olivine and pyroxene compositions with $\mathrm{FeO} /(\mathrm{FeO}+\mathrm{MgO})=0.22$ (based on MUELLER, 1964).

\begin{tabular}{rcc}
\hline \hline $\mathrm{T}{ }^{\circ} \mathrm{C}$ & "K" $=\mathrm{P}_{\mathrm{H}_{2}} / \mathrm{P}_{\mathrm{H}_{2} \mathrm{O}}$ & $\begin{array}{c}\mathrm{H}_{2} \text { depletion factor } \\
\text { relative to } \mathrm{H}_{2} / \mathrm{H}_{2} \mathrm{O} \text { ratio } \\
\text { in solar nebula }\end{array}$ \\
\hline 400 & 132 & 6 \\
600 & 35 & 52 \\
800 & 17 & 108 \\
1,000 & 11 & 166 \\
1,200 & 7.6 & 240 \\
1,400 & 6 & 305 \\
\hline
\end{tabular}

1 GROSSMAN (1972).

" $K$ " values for the above equilibrium corresponding to an $\mathrm{FeO} /(\mathrm{FeO}+\mathrm{MgO})$ ratio of 0.22 in the silicates, based on MUELLER's results are given in Table 4. Also shown are the relevant depletions in $\mathrm{H}_{2} / \mathrm{H}_{2} \mathrm{O}$ ratios (as compared to the solar $\mathrm{H}_{2} / \mathrm{H}_{2} \mathrm{O}$ ratios) which are needed to achieve this equilibrium at various temperatures. It is seen that for tempratures higher than $800^{\circ} \mathrm{C}, \mathrm{H}_{2}$ must be lowered relative to $\mathrm{H}_{2} \mathrm{O}$ by factors exceeding 100 to provide an environment possessing $\mathrm{H}_{2} / \mathrm{H}_{2} \mathrm{O}$ smaller than 17 (Table 4).

A fractionation of this nature cannot be accomplished in the gas phase. It is more readily explained by the enrichment with respect to hydrogen of a low-temperature, highly oxidized primordial condensate similar to $\mathrm{Cl}$ chondritic material. One mechanism for achieving this would be for the condensate from a cool region of the solar nebula to sink under gravity to the ecliptic plane where it would be strongly concentrated relatively to hydrogen (WooD, 1963). When allowance is made for the oxygen occurring as $\mathrm{H}_{2} \mathrm{O}, \mathrm{SO}_{4}^{--}, \mathrm{CO}_{3}^{--}$and $\mathrm{Fe}_{2} \mathrm{O}_{3}$ in $\mathrm{Cl}$ chondrites (section $5 \mathrm{~b}$ ), we find that about 34 percent of the total oxygen in the nebula would be present in the low-temperature Cl-like condensate. Accordingly, dust must be concentrated relative to gas by a factor of over 300 in order to provide a net gaseous $\mathrm{H}_{2} / \mathrm{H}_{2} \mathrm{O}$ ratio smaller than 17 which would permit condensation of substantial amounts of $\mathrm{FeO}$ at temperatures above $800^{\circ} \mathrm{C}$ (Table 4). The resultant system would comprise about 70 percent by weight of $\mathrm{Cl}$ condensate and 30 percent by weight of gases, mainly hydrogen.
If this system were heated above $800^{\circ} \mathrm{C}$ by an appropriate mechanism, volatile metals would be evaporated whilst the solid condensate would consist dominantly of $(\mathrm{Mg}, \mathrm{Fe})_{2} \mathrm{SiO}_{4},(\mathrm{Mg}, \mathrm{Fe})$ $\mathrm{SiO}_{3}, \mathrm{FeS}$ and metallic $\mathrm{FeNi}$. If the condensate were then separated from the gas and collected into planetesimals which accreted to form the earth, the required loss of volatiles combined with entry of $\mathrm{FeO}$ into the earth might be explained. We note in passing that the same process would also permit the condensation of a large portion of the primordial complement of sulphur, as described in Section 2.

(b) Physical mixing of high temperature and low temperature condensates Whereas the mechanism described above envisages the formation of the earth from a chemically uniform batch of condensate formed in a relatively homogeneous but fractionated region of the nebula, we can envisage an alternative process by which the earth was formed by physical mixing of batches of material which had equilibrated under very different $\mathrm{P}, \mathrm{T}$ conditions and which therefore possessed highly contrasting compositions. The simplest example of this is a two-component model whereby the earth is interpreted in terms of a mixture of highly reduced, metal-rich, devolatilized material formed at high temperatures with a smaller amount of primordial, oxidized, volatile-rich material similar to $\mathrm{Cl}$ chondrites and formed at low temperatures. Two-component models of this kind were first proposed for the earth by RiNGwOoD (1960), for chondritic meteorites by Wood (1963) and for the moon by RINGWood (1966b). They have since been further developed by ANDERS and coworkers for meteorites (ANDERS, 1964, 1968, 1971) and for the moon and earth (GANAPATHY and ANDERS, 1974).

Models of this type are attractive since they account for the fact that although markedly depleted in volatiles, the earth has nevertheless retained an appreciable proportion of the primordial complement of $\mathrm{Na}, \mathrm{K}, \mathrm{Zn}, \mathrm{Pb}$ and other volatiles. The homogeneous accretion model described in section 5a does not account for this abundance pattern as readily.

We next enquire how well the present bulk composition of the earth can be matched in terms of this two-component model, particularly with regard to the entry of $\mathrm{FeO}$ and $\mathrm{FeS}$ into the earth. Compositions of the oxidized, volatile-rich, low temperature component (A) and the reduced, devolatilized, metal-rich high 
temperature component (B) are given in Table 5. We will consider a model comprising 15 percent of component $\mathrm{A}$ and 85 percent of component $\mathrm{B}$.

Table 5. Compositions of Orgueil Cl chondrite and of reduced, devolatilized component condensing at elevated temperatures $\left(\sim 1,000^{\circ} \mathrm{C}\right)$ in solar nebula.

\begin{tabular}{lcc}
\hline & $\begin{array}{c}\text { Orgueil }^{1} \\
\mathrm{~A}\end{array}$ & $\begin{array}{c}\text { High temp. } \\
\text { component } \\
\text { B }\end{array}$ \\
\hline $\begin{array}{l}\text { Metallic nickel-iron } \\
(\sim 5 \% \mathrm{Ni})\end{array}$ & - & 34.1 \\
$\mathrm{SiO}_{2}$ & 21.7 & 32.8 \\
$\mathrm{TiO}_{2}$ & 0.1 & 0.2 \\
$\mathrm{Al}_{2} \mathrm{O}_{3}$ & 1.6 & 2.8 \\
$\mathrm{Cr}_{2} \mathrm{O}_{3}$ & 0.35 & 0.2 \\
$\mathrm{MnO}$ & 0.2 & 0.1 \\
$\mathrm{FeO}$ & 22.9 & - \\
$\mathrm{NiO}$ & 1.2 & - \\
$\mathrm{MgO}$ & 15.2 & 27.7 \\
$\mathrm{CaO}$ & 1.2 & 2.3 \\
$\mathrm{Na}{ }_{2} \mathrm{O}$ & 0.7 & - \\
$\mathrm{K}_{2} \mathrm{O}$ & 0.07 & - \\
$\mathrm{P}_{2} \mathrm{O}_{5}$ & 0.3 & - \\
Water $_{\text {Organic compounds }}$ & 19.2 & - \\
Sulphur & 9.7 & - \\
& 5.7 & - \\
\hline
\end{tabular}

1 WIIK (1956).

2 Based on bulk composition of earth (RINGWOOD, 1975) minus volatile alkalis and with all oxidized iron reduced to the metallic state.

The earth contains about 8 percent " $\mathrm{FeO}$ " $\left(\mathrm{FeO}+\mathrm{Fe}_{2} \mathrm{O}_{3}+\mathrm{NiO}\right.$ ) in its mantle (RINGWOOD, 1975) which contributes $5.4 \% \mathrm{FeO}$ in the bulk earth. According to the discussion in section $4 \mathrm{e}$, the core might also contain about 44 percent of $\mathrm{FeO}$. This would imply a total of 20 weight percent $\mathrm{FeO}$ in the earth. The addition of 15 percent of component $\mathrm{A}(22.9 \% \mathrm{FeO}+$ $1.2 \% \mathrm{NiO}$ ) would provide directly only 3.6 percent $\mathrm{FeO}$ for the entire earth, far less than is inferred to be present.

There is, however, much more oxygen present in other forms in component A which is available to combine with metallic iron from component $\mathrm{B}$ to form $\mathrm{FeO}$. The analysis (Table 5) shows $19.2 \% \mathrm{H}_{2} \mathrm{O}$. When mixed with metallic iron, during accretion, the latter is oxidized:

$$
\mathrm{Fe}+\mathrm{H}_{2} \mathrm{O}=\mathrm{FeO}+\mathrm{H}_{2}
$$

Most of the hydrogen is lost but some enters into solution in excess metallic iron which is present (RINGWOOD, 1975) ${ }^{1}$. Most of the 5.7 percent of sulphur in component $\mathrm{A}$ is present as $\mathrm{SO}_{4}^{-2}$ whilst a significant proportion of carbon occurs as $\mathrm{CO}_{3}^{-2}$ (MASON, 1963, 1971). Much of the oxidized iron present in component $\mathrm{A}$ occurs as $\mathrm{Fe}_{2} \mathrm{O}_{3}$. The complex organic compounds in component $\mathrm{A}$ also contain about 12 percent of combined oxygen (HAYES, 1967) whilst some excess oxygen is combined with phosphorus, most of which ultimately enters the earth's core. The oxygen in all of these reservoirs will be reduced by metallic iron to form $\mathrm{FeO}$ when components $\mathrm{A}$ and $\mathrm{B}$ are mixed during accretion of the earth.

The distribution of "excess" oxygen between these phases is not clearly defined in bulk chemical analyses such as those of W IIK (1956). Most of the excess oxygen is formally calculated as $\mathrm{H}_{2} \mathrm{O}$ in his investigation (Table 5) even though a substantial proportion occurs as sulphate and carbonate. We obtain from this analysis an excess oxygen content of 18.4 weight percent based upon the oxygen formally contained in $\mathrm{H}_{2} \mathrm{O}$, organic compounds and $\mathrm{P}_{2} \mathrm{O}_{5}$. Assuming an addition of 15 weight percent of the low temperature A component, this is sufficient to produce 12.4 percent $\mathrm{FeO}$ by oxidizing $\mathrm{Fe}$ (metal) present in component B. Combining this with the $3.6 \% \mathrm{FeO}$ initially present in 15 percent of component $\mathrm{A}$, the total $\mathrm{FeO}$ content of the mixture of $15 \% \mathrm{~A}+85 \% \mathrm{~B}$ (Table 1) is $16 \% \mathrm{FeO}$. A bulk earth model possessing this amount of $\mathrm{FeO}$ would contain 33 weight percent of $\mathrm{FeO}$ in the core, or 7.3 weight percent of oxygen. Accoridng to this model, the core would also contain 2.7 percent of sulphur and up to 2.8 percent of carbon. The total content of light elements in the core would thus amount to 13 weight percent. Although the amount of $\mathrm{FeO}$ calculated above to be present in the earth's core $(33 \%)$ is substantially smaller than that estimated in section $4 \mathrm{~d}(44 \% \mathrm{FeO})$, the uncertainty in the latter estimate is large and the difference is not significant. When the effects of the additional sulphur and carbon are considered, it seems clear that the above core model would be able to account for the observation that the

1 STEVENSON (1977) concluded that solution of hydrogen in iron would cause a marked decrease in density of the alloy despite the interstitial nature of the solution. A small amount of hydrogen may have entered the earth's core via the above equilibria. 
density of the core is about 8 percent smaller than that of pure $\mathrm{Fe}$ metal under the same $\mathrm{P}, \mathrm{T}$ conditions (MCQueEN and MARSH, 1966). ${ }^{1}$

A key implication of the two-component earth model discussed above is that the principal light element in the core is oxygen, not sulphur.

\section{(c) Application of two-component model to} the earth's mantle The abundance patterns of volatile elements in the earth's mantle in relation to primordial abundances displayed by $\mathrm{Cl}$ chondrites have recently been discussed by RINGWOOD and Kesson (1977). Their results are shown in Fig. 1. Involatile elements such as $\mathrm{Mg}, \mathrm{Ca}, \mathrm{Al}, \mathrm{U}, \mathrm{Ti}$ have similar relative abundances in the mantle and in $\mathrm{Cl}$ chondrites. However, elements more volatile than $\mathrm{Mg}$ are depleted by varying factors in the mantle. The general sequence of increasing depletion factors corresponds quite well to the condensation sequence in Table 1 and leaves little doubt that the terrestrial depletions are primarily a consequence of selective condensation/volatilization processes. In some cases (e.g., $\mathrm{Cu}, \mathrm{Ag}, \mathrm{Ge}, \mathrm{S}$, Se), depletions in the mantle are also caused in part by their siderophile nature which has resulted in preferential entry into the earth's core. If we consider the elements with depletion factors between 1.0 and 0.05 , there is a strong correlation between condensation temperature and degree of depletion. Copper and silver would doubtless have come higher in the sequence if allowance had been made for the amount of these elements which entered the core.

There is a big jump from the non-siderophile but highly volatile elements $\mathrm{Zn}, \mathrm{Cl}$, In, Cs (depletion factors $0.05-0.08$ ) to $\mathrm{Tl}, \mathrm{Bi}, \mathrm{Pb}, \mathrm{Cd}, \mathrm{Ge}$ (depletion factors 0.03-0.01). These latter elements are of comparable volatility but show substantial $(\mathrm{Pb})$ to strong $(\mathrm{Ge})$ siderophile tendencies. Ringwood and Kesson (1977) thus concluded that the excess depletions of these elements in the mantle were caused by entry into the core. The amount of the low-temperature component $\mathrm{A}$ in the earth is therefore estimated on the basis of the abundances of $\mathrm{Zn}$, $\mathrm{Cl}$, In and $\mathrm{Cs}$ in the earth's mantle. When normalized to a major non-volatile element (e.g. $\mathrm{Mg}$ ) and converted to whole-earth abundances, the depletion factors for these elements imply that the earth collected about 10 weight percent of the low-temperature oxidized, volatile-rich component $\mathrm{A}$, the bulk composition of which is given in Table 5 .

The excess oxygen contained in 10 percent of component A, would yield a core containing 16 percent of $\mathrm{FeO}$, after allowing for the $\mathrm{FeO}$ which enters the mantle. This amount of $\mathrm{FeO}$ in the core would not be large enough to explain the lower density of the core as compared to pure iron. The amount of component A required for this purpose was previously estimated as 15 percent. We should recall, however, that the $\mathrm{Cl}$ chondrites on which the composition of component $\mathrm{A}$ was based have probably been subjected to a mild degree of recrystallization and metamorphism in a parent body, during which some volatiles were lost (RINGwOOD, 1963). The primordial dust condensing at low temperatures in the solar nebula probably contained much more excess oxygen (as $\mathrm{H}_{2} \mathrm{O}$, $\mathrm{CO}_{3}^{-2}$ and $\mathrm{SO}_{4}^{-2}$ ) than $\mathrm{Cl}$ chondrites. Thus, if all of the sulphur and half of the carbon now present in $\mathrm{Cl}$ chondrites were present in the primordial condensate as $\mathrm{SO}_{4}^{-2}$ and $\mathrm{CO}_{3}^{-2}$, respectively, and in addition some 20 percent of water occurred in the form of hydrated minerals, the total excess oxygen present would amount to 37 percent. Ten percent of this component A would thus provide about 40 percent of $\mathrm{FeO}$ in the core after allowing for the observed amount of $\mathrm{FeO}$ in the mantle.

(d) Discussion It is not intended in the present study to examine in detail the conditions under which the earth accreted. This is the objective of a companion paper (RINGWOOD, 1977). In the previous discussion, we considered two distinct chemical models of the solar nebula which would have permitted the earth to incorporate substantial quantities of light elements in the core. The first of these (section 5a) involving accretion at high temperatures in a region of the solar nebula depleted in hydrogen would imply, in the light of conclusions reached in sections $2 \mathrm{~d}, 4 \mathrm{c}$ and $4 \mathrm{~d}$, that the principal light elements in the earth's core are sulphur and oxygen in comparable amounts. The second model, according to which the earth is viewed as accreting from a mixture of high temperature $(\sim 90 \%)$ and low-temperature

1 The presence of a small amount of hydrogen in the core as mentioned in the footnote on page 125 might also contribute to the density deficit (STEVENSON, 1977), and also reduce somewhat the amount of component $A$ required in the model. 
$(\sim 10 \%)$ nebula condensates implies that oxygen is the principal light element in the core, although significant amounts of sulphur and carbon may also be present.

It seems quite likely that the conditions operating during accretion of the earth may have involved essential elements of both models. Nevertheless, if the abundances of volatile elements (e.g., $\mathrm{Zn}, \mathrm{Cs}, \mathrm{Cl}, \mathrm{In}, \mathrm{Pb}$ ) in the mantle are to be explained, a major role must be ascribed to the second model. The first model is unable, alone, to account for the abundances of volatile elements in the mantle. These topics are considered in greater detail in a companion paper (RINGWOOD, 1977).

The preceding discussion leads to the conclusion that oxygen is probably the principal light element present in the earth's outer core, although significant amounts of sulphur and carbon may also be present.

6. Some Geochemical Implications of the Presence of FeO in the Core

(a) Siderophile elements and oxidized species in the mantle According to a widely discussed hypothesis (e.g., UREY, 1952; BIRCH, 1965), the earth was formed by accretion in the solar nebula from an intimate mixture of nickel-iron and silicate particles. After or during accretion, extensive melting occurred, thereby permitting the metal phase to segregate into large bodies which sank into the deep interior of the earth to form the core. This model implies that the distribution of siderophile elements between the metal and silicate phases closely approached (local) equilibrium. A remarkable feature of the geochemistry of the upper mantle, however, is that the abundances of many siderophile elements, e.g., $\mathrm{Ni}, \mathrm{Co}, \mathrm{Re}$, $\mathrm{Os}, \mathrm{Ir}, \mathrm{Pt}, \mathrm{Cu}, \mathrm{Ge}, \mathrm{As}$ and $\mathrm{Au}$ are from 10 to 1,000 times higher than would be expected if equilibrium with metal had prevailed (RINGwOOD, 1966a, b; RINGWOOD and KESSON, 1977). It is clear that the earth's upper mantle has never been in equilibrium with metallic iron.

This inference is supported by evidence from another direction. The upper mantle contains substantial amounts of ferric iron. In order to explain the $\mathrm{Fe}^{3+} / \mathrm{Fe}^{2+}$ ratios of fresh oceanic basaltic glasses and of unaltered primary mantle minerals (from xenoliths in alkali basalts and alpine peridotites), an $\mathrm{Fe}^{3+} / \mathrm{Fe}^{2+}$ ratio of 0.05 to 0.1 is required for the primary source region (pyrolite) in the upper mantle. On the other hand, the $\mathrm{Fe}^{3+} / \mathrm{Fe}^{2+}$ ratios of basalts, pyroxenes and spinels which have equilibrated with metallic iron at high temperatures are much lower, probably by at least an order of magnitude (R INGWOOD, 1966b, 1971).

This difference in oxidation states is reflected in the nature of the volatiles developed by degassing (Table 6). It is well known that the volatiles degassed from the earth are dominantly composed of $\mathrm{H}_{2} \mathrm{O}$ and $\mathrm{CO}_{2}$ rather than $\mathrm{H}_{2}$ and $\mathrm{CO}$. Thus, the gas phase in equilibrium with an average Hawaiian tholeiite at $1,200^{\circ} \mathrm{C}$ would have $\mathrm{H}_{2} \mathrm{O} / \mathrm{H}_{2} \sim 120$ and $\mathrm{CO}_{2} / \mathrm{CO} \sim 35$ (Holland, 1963). These ratios agree closely with RUBEY's (1951) estimates for the composition of volatiles degassed from the earth. The observed composition of the gas phase is thus compatible with the oxidation state of the pyrolite mantle which indeed constitutes the ultimate redoxstate buffer. On the other hand, if the mantle had equilibrated with metallic iron, the gas phase evolved would be dominated by $\mathrm{CO}$ and $\mathrm{H}_{2}$ rather than $\mathrm{CO}_{2}$ and $\mathrm{H}_{2} \mathrm{O}$ (Table 6).

(b) Accretion of the earth

The relatively high abundances of siderophile elements and oxidized species in the upper mantle show clearly that this region could not have equilibrated with metallic iron. This conclusion has an important bearing upon the mechanism of core formation in the earth. RINGWOOD (1966a, b, 1971) and BRETT (1971) considered the possibility that high pressures deep in the mantle might have caused large increases in the distribution coefficients of some siderophile elements between metal and silicates. Although this is possible, even likely in specific cases, RINGWOOD rejected this as a general explanation since it would have been highly coincidental for pressure to change all of these partition coefficients in the same sense.

Accordingly, RiNGwOOD (1966a, b, 1975) rejected the conventional models of homogeneous accretion which maintained that the earth had formed from an intimate mixture of metal particles and silicate particles produced in the solar nebula, followed by melting and differentiation to form the core. He proposed instead, a model of inhomogeneous accretion of the earth. According to this hypothesis (see also, RinGwOOD, 1960), the earth accreted from primitive oxidized planetesimals resembling Type 1 carbonaceous chondrites. The temperature distribution during accretion was controlled by the gravitational potential energy 
Table 6. Composition of gas phases in equilibrium with mantle-type mineral assemblage in the presence and absence of metallic iron at $1,200^{\circ} \mathrm{C}$.

\begin{tabular}{ccccc}
\hline Mineral assemblage & $\mathrm{fO}_{2}$ atm. & $\mathrm{Fe}^{2+} / \mathrm{Fe}^{3+}$ & $\mathrm{CO}_{2} / \mathrm{CO}$ & $\mathrm{H}_{2} \mathrm{O} / \mathrm{H}_{2}$ \\
$\mathrm{Mg} /(\mathrm{MgO}+\mathrm{FeO}) \approx 0.9$ & $10^{-8}$ & $\sim 15$ & 35 & 120 \\
Olivine + pyroxene $(s)+$ spinel & $10^{-14}$ & $\sim 200$ & 0.05 & 0.1 \\
Olivine + pyroxene $(s)+$ spinel + iron & & \\
\hline
\end{tabular}

Based on Holland, 1963; MUELLER, 1964; RiNGWOOD, 1975.

liberated when the planetesimals were swept up by the earth. This increases in proportion to the square of the radius. Thus, during the early stages of accretion, a cool oxidized volatile-rich nucleus of $\mathrm{Cl}$ chondrite-type composition was formed. This became surrounded by a more reduced assemblage of metal and silicates, formed under higher temperatures, as the size of the growing earth and its accretional energy increased. In this model, segregation of the metal phase to form the core was believed to have occurred very rapidly once a threshold temperature was exceeded, and was accompanied by a violent convective episode which caused the inner nucleus of low-temperature condensate (containing siderophile elements) to become thoroughly mixed into the mantle, but under conditions whereby complete equilibration with rapidly-sinking large bodies of metallic iron did not prevail.

Another version of the heterogeneous accretion hypothesis was proposed by TUREKIAN and CLARK (1969) who suggested that after segregation of metal into the core, the earth swept up a population of late stage planetesimals which had formed when the solar nebula had cooled to low temperatures. These were of primordial composition, i.e., highly oxidized and rich in volatiles, being generally similar to Type 1 carbonaceous chondrites. Because they were added to the upper mantle after the core had formed, the problems raised by equilibration with metal were avoided.

Although this latter model has received a degree of favourable attention in the literature, it is beset by numerous problems, most of them fatal. A detailed statement of these is given by RINGWOOD (1975, pp. 558-563, 1977) and by RINGWOOD and KESSON (1977). The model can be firmly rejected.

Whilst many of the problems encountered by the latter heterogeneous accretion model are avoided by RinGwOoD's (1960, 1966a, b) version of this model, both versions nevertheless encounter two difficulties which may not be readily solved. These are discussed below. (i) The dispersions of abundances of some siderophile and volatile elements, e.g., $\mathrm{Ni}, \mathrm{Co}$, $\mathrm{Ge}, \mathrm{Ga}, \mathrm{Zn}$ in the rocks of the upper mantle appear to be surprisingly low. In fresh ultramafic rocks of mantle origin, the vast majority of $\mathrm{Ni}$ and $\mathrm{Co}$ abundances are within \pm 50 percent of the mean values (Goles, 1967; STEUbER and Goles, 1967); likewise for $\mathrm{Co}, \mathrm{Ga}$ and $\mathrm{Ge}$ in ocean floor tholeiites and hence also in their source regions (FREY et al., 1974; ARGOllo, 1974; WEDEPOHL, 1974). The dispersion of $\mathrm{Zn}$ abundances in ultramafic rocks and in basalts also appear to be low (RADER et al., 1963; BAEDECKER et al., 1971; WEDEPOHL, 1974; Gurney and Ahrens, 1973). According to the heterogeneous accretion hypothesis, siderophile and volatile elements were incorporated into the mantle via the mechanical mixing of a small amount of highly oxidized, volatile-rich primordial material with a large reservoir of highly reduced, devolatilized material. The mixing process is believed to be driven by convective motions caused by core-formation. However, it is not clear whether this mixing process could have possessed the extraordinary efficiency needed to account for the small dispersions of abundances of many siderophile and volatile elements, and also of $\mathrm{FeO}$, (possibly at the centimeter-size scale) in the earth's upper mantle. It must be admitted that the apparent uniformity of distribution of these siderophile and volatile elements in the upper mantle would be more readily accounted for if the earth had accreted from an intimate mixture of hightemperature and low-temperature condensates, the mixing occurring in the nebula prior to accretion; providing the other difficulties associated with this model and discussed previously are disregarded.

(ii) If the oxidized nickel now present in the mantle had been introduced in the form of a low-temperature, metal-free condensate, as in the heterogeneous accretion model, then this condensate should contain the primordial abundances of all elements (Table 1) which are fully condensed above $400^{\circ} \mathrm{K}$. (At temperatures 
higher than this, nickel would be present entirely in a metallic phase.) For example, germanium which condenses at $820^{\circ} \mathrm{K}$ should be present in the low-temperature condensate in an amount corresponding to the primoridal $\mathrm{Ni} / \mathrm{Ge}$ ratio of 360. However, the observed $\mathrm{Ni} / \mathrm{Ge}$ ratio in the upper mantle is 2,060 (RINGWOOD and KESSON, 1977). Because of the small dispersions of $\mathrm{Ge}$ and $\mathrm{Ni}$ in the mantle rocks, this ratio is firmly established. Moreover, on the basis of this model, the mantle should also contain the primordial $\mathrm{Ni} / \mathrm{Ir}$ ratio of $7.8 \times 10^{4}$ whereas the observed ratio is $3.3 \times 10^{6}$ (RINGwOOD and KESSON, 1977).

\section{(c) Reconsideration of homogeneous accretion} model The solution of large quantities of ferrous oxide in the core would considerably affect the redox state of the mantle-core system, the corresponding distribution of siderophile elements between mantle and core, and the abundances of oxidized species in the mantle.

Consider the case where mantle silicates containing $\mathrm{FeO}$ are in equilibrium with pure metallic iron.

$$
2 \mathrm{Fe}+\mathrm{O}_{2}=2 \mathrm{FeO}
$$

The equilibrium constant $\mathrm{K}=\mathrm{a}_{\mathrm{FeO}}^{2} / \mathrm{a}_{\mathrm{Fe}}^{2} \cdot \mathrm{f}_{1}\left(\mathrm{O}_{2}\right)$ where $\mathrm{a}_{\mathrm{FeO}}$ is the activity of $\mathrm{FeO}$ in the mantle, $\mathrm{a}_{\mathrm{Fe}}$ is the activity of iron (equal to unity) and $\mathrm{f}_{1}$ is the fugacity of oxygen. Thus, $\mathrm{K}=\mathrm{a}_{\mathrm{FeO}}^{2} /$ $\mathrm{f}_{1}\left(\mathrm{O}_{2}\right)$. Now, consider the case where the core contains a large quantity of dissolved $\mathrm{FeO}$ so that the activity of $\mathrm{Fe}$ is lowered, whilst $\mathrm{a}_{\mathrm{FeO}}$ in the mantle remains fixed. The fugacity of oxygen changes to $f_{2}\left(\mathrm{O}_{2}\right)$ and the equilibrium constant is $\mathrm{a}_{\mathrm{FeO}}^{2} / \mathrm{a}_{\mathrm{Fe}}^{2} \cdot \mathrm{f}_{2}\left(\mathrm{O}_{2}\right)$. Equating the equilibrium constants, cancelling $\mathrm{a}_{\mathrm{FeO}}^{2}$ terms and rearranging, we have

$$
\frac{\mathrm{f}_{2}}{\mathrm{f}_{1}}\left(\mathrm{O}_{2}\right)=\frac{1}{\mathrm{a}_{\mathrm{Fe}}^{2}}
$$

The activity of iron in the $\mathrm{Fe}-\mathrm{FeO}$ solution may well be considerably decreased compared to its pure state. Applying equation IV, it seems quite possible that the oxygen fugacity $\left(\mathrm{f}_{2}\right)$ in regions of the earth's mantle which had equilibrated with $(\mathrm{FeO}-\mathrm{Fe})$ solutions prior to and during core formation could be a few log units higher than in the case $\left(f_{1}\right)$ where solution of $\mathrm{FeO}$ did not occur. Under such circumstances the abundances of $\mathrm{Fe}^{3+}, \mathrm{H}_{2} \mathrm{O}$ and $\mathrm{CO}_{2}$ in the mantle might have been established under equilibrium conditions. Likewise, the higher $\mathrm{f}\left(\mathrm{O}_{2}\right)$ conditions could cause considerable increases in the equilibrium amounts of siderophile elements which entered the mantle. The high abundances of these elements might thus also be attributed to equilibrium partition between $(\mathrm{Fe}-\mathrm{FeO})$ metallic liquid and silicates.

The apparent uniformity in distribution of several volatile and siderophile elements in the earth's upper mantle might thus represent a combination of equilibrium partitions between metal and silicate phases in the deep mantle combined with convective mixing during core formation and also, subsequent to core-formation. It has been concluded elsewhere, on the basis of the irreversible differentiation of the mantle manifested in plate tectonic processes and in the evolution of the earth's crust, that the material now in the upper mantle may ultimately have been derived via convective motions, from the deep mantle (RINGWOOD, 1969, 1972, 1975; DiCKINSON and LUTH, 1971).

The equilibrium model for the distribution of elements between metal and silicate phases during core formation might also provide an explanation for other puzzling geochemical characteristics of the mantle, not readily explained by the heterogeneous accretion model, e.g., the observations that the relative abundances of many siderophile and volatile elements in the upper mantle deviate strongly from the primordial relative abundances, as discussed earlier.

It will be interesting in the future to see whether the equilibrium model combined with homogeneous accretion is able to explain the relative abundances of gold and platinum-group metals in the mantle. These appear to possess very wide dispersions in their abundances, but it is not clear to what extent these dispersions may have been caused by crystal chemical factors arising from mantle differentiation processes combined with near-surface metasomatism. Perhaps the wide dispersions of these elements may require a continuing role for an element of the heterogeneous accretion hypothesis. Much more data will be required before this question can be settled.

(d) Iron oxide content of the mantle One of the most striking characteristics of mantlederived alpine ultramafics and lherzolite xenoliths in alkali basalts is their uniformity of $\mathrm{FeO} /(\mathrm{FeO}+\mathrm{MgO})$ ratios, which mostly lie 
within the range 0.08 to 0.11 (molecular). Likewise, the $\mathrm{FeO} /(\mathrm{FeO}+\mathrm{MgO})$ ratios of those oceanic tholeiites which have not been subjected to high-level crystallization differentiation also appear to be relatively uniform and close to 0.34 . These displays of uniformity on a worldwide basis imply that a corresponding degree of uniformity in $\mathrm{FeO} /(\mathrm{FeO}+\mathrm{MgO})$ ratios extends to large proportions of the upper mantle, both on a regional and local scale. The overall uniformity in the spectrum of basalt compositions throughout geological time, and the compositions of older alpine ultramafic complexes suggest that the present mean $\mathrm{FeO} /(\mathrm{FeO}+\mathrm{MgO})$ of the upper mantle has been characteristic of this region since the early Precambrian.

The gross physical properties of the lower mantle are well explained on the basis of phase transformations occurring in material, which, to a first approximation, has an overall chemical composition similar to that of the upper mantle (RINGWOOD, 1975). Except perhaps in the lowermost $200 \mathrm{~km}$, there is no evidence which requires that the $\mathrm{FeO} /(\mathrm{FeO}+\mathrm{MgO})$ ratio of the lower mantle differs from that of the upper mantle. The large degree of convective circulation within the mantle required by the hypothesis of plate tectonics suggests that much of the material now eonstituting the upper mantle may ultimately have been derived from the deep mantle (DICKINSON and LUTH, 1971; RingwOOD, 1975). Moreover, the process of core segregation must have involved a rather comprehensive convective circulation of the entire mantle.

RiNGwOOD (1960, 1966b) had previously attributed the introduction of $\mathrm{FeO}$ into the mantle to a process of mechanical mixing of two components, possessing contrasting compositions (one reduced and the other oxidized), following formation of the earth by heterogeneous accretion. However, the remarkable degree of uniformity in $\mathrm{FeO} /(\mathrm{FeO}+\mathrm{MgO})$ ratios among most mantle-derived lherzolite xenoliths and alpine ultramafics is not readily explained by a process relying basically upon mechanical mixing, which is unlikely to possess the required efficiency. RinGwOOD (1975) attempted an alternative explanation of the uniformity of $\mathrm{FeO} /(\mathrm{FeO}+\mathrm{MgO})$ ratios in terms of $\mathrm{H}_{2} / \mathrm{H}_{2} \mathrm{O}$ gas buffering during accretion of the earth. Although possible in principle, this hypothesis requires rather demanding assumptions.

It is tempting to seek an explanation for these small variances in $\mathrm{FeO} /(\mathrm{FeO}+\mathrm{MgO})$ ratios in terms of similar processes to those which were responsible for inferred small variances of compatible siderophile elements (e.g. $\mathrm{Ni}, \mathrm{Co}, \mathrm{Ge}$, $\mathrm{Ga}$ ), and of compatible volatile elements (e.g. $\mathrm{Zn}, \mathrm{Ge}, \mathrm{Ga}, \mathrm{Mn})$ in the upper mantle, and the occurrence of oxidized species (e.g. $\mathrm{Fe}^{3+}, \mathrm{CO}_{2}$, $\mathrm{H}_{2} \mathrm{O}$ ) in this region, as discussed in section $6 \mathrm{a}$, $\mathrm{b}$ and $\mathrm{c}$.

We concluded earlier, that if the earth accreted homogeneously from a mixture of metal and silicate, the solubility of $\mathrm{FeO}$ in the liquid metal phase would increase strongly with depth, once the solidus of the $\mathrm{Fe}-\mathrm{FeO}$ system was exceeded. Accordingly, the $\mathrm{FeO} /(\mathrm{FeO}+\mathrm{MgO})$ ratio of the coexisting silicate and oxide phases would decrease with depth.

It is likely that at very high pressures, the system $\mathrm{Fe}-\mathrm{FeO}$ may behave analogously to the system $\mathrm{Fe}-\mathrm{FeS}$ at low pressures (section $5 \mathrm{c}$ ). Thus, an extensive degree of solubility of $\mathrm{FeO}$ (or $\mathrm{Fe}_{3} \mathrm{O}_{4}$ ) in molten iron is expected to cause a large decrease in the $\mathrm{Fe}^{-} \mathrm{FeO}^{*}$ solidus (eutectic) temperature as compared to the melting point of pure iron. For this reason, melting of metal phase leading to segregation of large bodies of liquid $\left(\mathrm{Fe}-\mathrm{FeO}^{*}\right)$ solution is likely to commence first at great depths within the earth (in contrast to the ElSASSER, 1963, model wherein the core-segregation process commences near the surface). The effect of dissolved $\mathrm{FeO}$ on melting point of the metallic alloy also ensures that the metal phase melts at a much lower temperature than the silicate phase at the high pressures attained deep within the earth's interior.

The commencement of core segregation at great depths causes acute convective instability in the overlying regions. This is accentuated because of the decrease in $\mathrm{FeO} /(\mathrm{FeO}+\mathrm{MgO})$ ratio of the silicate-oxide phases with depth as $\mathrm{FeO}$ enters the metal phase. After segregation of metal from a localized region, the residual silicate-oxide phase rises convectively or diapirically upward, to be replaced by a new batch of dense FeO-rich silicate and metal mixture from the upper mantle. This new batch quickly re-equilibrates. $\mathrm{FeO}$ migrates from silicate-oxide phase into the molten metal phase which segregates and sinks into the core. The $\mathrm{FeO}$ content of the residual silicate-oxide phase is thus established by high pressure equilibrium with $\left(\mathrm{Fe}-\mathrm{FeO}^{*}\right)$ metal phase, deep within the earth. Ultimately, the entire volume of the earth is convectively recycled in this manner and all of the metal enters the core. One of the principal results of this process is to produce a 
fairly uniform mean $\mathrm{FeO} /(\mathrm{FeO}+\mathrm{MgO})$ ratio in the silicate-oxide phase, this ratio reflecting equilibria established ultimately in the deep mantle.

An analogous situation is envisaged in a hypothesis advanced by MAO (1974) which maintains that ferrous iron is likely to disproportionate into ferric iron plus metallic iron in the deep mantle. Of the reactions considered by MAO, the most probable is (simplified):

$$
4 \mathrm{FeO} \rightarrow \mathrm{Fe}_{3} \mathrm{O}_{4}(\mathrm{hpp})+\mathrm{Fe}(\epsilon) .
$$

Because of entropy considerations discussed earlier, some undisproportionated $\mathrm{FeO}$ will remain in solid solution in the rocksalt and perovskite phases of the lower mantle. We suggest that this region attains a final composition corresponding to an $\mathrm{FeO} /(\mathrm{FeO}+\mathrm{MgO})$ ratio of 0.12 .

According to MAO's model, a separate $\mathrm{Fe}_{3} \mathrm{O}_{4}$ (hpp) phase is produced by disproportionation of $\mathrm{FeO}$ in the lower mantle. He suggests that this phase remains behind after segregation of metallic iron into the core. Metal-free material from this region then rises convectively into the upper mantle, carrying the $\mathrm{Fe}_{3} \mathrm{O}_{4}(\mathrm{hpp})$ phase. Retrogressive transformation of the deep mantle mineral assemblage into a lower pressure upper mantle assemblage then occurs. The latter will therefore be characterized by the presence of considerable amounts of ferric iron derived from the $\mathrm{Fe}_{3} \mathrm{O}_{4}$ (hpp), a component which is required to explain the redox state of this region. $\mathrm{MAO}$ also points out that this process will cause the volatiles degassed from the upper mantle to be dominated by $\mathrm{CO}_{2}$ and $\mathrm{H}_{2} \mathrm{O}$.

MAO's hypothesis is most attractive in principle. However, it does not readily explain the observation that the proportion of ferric iron in the primordial upper mantle is quite small. Based upon the compositions of unaltered glassy selvedges of rapidly quenched oceanic tholeiite glasses and fresh peridotite xenoliths of mantle origin, the $\mathrm{Fe}^{3+} / \mathrm{Fe}^{2+}$ ratio of the primordial upper mantle is probably in the vicinity of 0.05 . MAO's model would be expected to yield a much larger $\mathrm{Fe}^{3+} / \mathrm{Fe}^{2+}$ ratio. In particular, if a substantial or large part of the earth's iron core had formed by this disporportionation reaction as suggested by BELL and MAO (1976), vast amounts of ferric iron should be present in the upper mantle.

According to the hypothesis developed in the present paper, the $\mathrm{Fe}_{3} \mathrm{O}_{4}(\mathrm{hpp})$ phase pro- duced by partial disproportionation of $\mathrm{FeO}$ in the deep mantle will be totally dissolved in excess liquid metallic iron once the melting temperature of the metallic $\left(\mathrm{Fe}-\mathrm{FeO}{ }^{*}\right)$ solution is exceeded substantially. However, under subsolidus conditions prior to core segregation, the lower mantle phases, e.g. $\left(\mathrm{Mg}_{0.88} \mathrm{Fe}_{0.12}\right) \mathrm{SiO}_{3}$ perovskite, will have equilibrated with $\mathrm{Fe}_{3} \mathrm{O}_{4}$ (hpp) and will therefore contain a small proportion of $\mathrm{Fe}_{2} \mathrm{O}_{3}$, which would possess limited solid solution in the perovskite phase. After the metallic $\left(\mathrm{Fe}-\mathrm{FeO}^{*}\right)$ phase has segregated into the core, the $\mathrm{Fe}^{3+}$-bearing perovskite will be returned to the upper mantle via convection, thereby accounting for the presence of a small amount of $\mathrm{Fe}^{3+}$ in this region and a redox state which ensures that the volatiles produced are dominated by $\mathrm{H}_{2} \mathrm{O}$ and $\mathrm{CO}_{2}$.

MAO (1974) suggested that because of convective transfer of material from the lower to the upper mantle, the high abundances of siderophile elements $(\mathrm{Ni}, \mathrm{Co}, \mathrm{Au}, \mathrm{Pt}, \mathrm{Ir}, \mathrm{Re})$ in the upper mantle may reflect high pressure equilibration between metal and silicates. This explanation, which implied that partitions of siderophiles are greatly altered because of the P. $\Delta \mathbf{v}$ terms in the metal-silicate exchange equilibria, was considered by RINGWOOD (1971). Although it may be applicable in specific cases, it does not appear satisfactory as a general explanation (section 6b).

The viewpoint adopted in this paper (section $6 c)$ is that the high concentrations of siderophile elements in the upper mantle may well reflect a high pressure equilibrium established in the deep mantle, controlled not by the volume factor, but primarily by oxygen fugacity. It was pointed out that extensive solution of $\mathrm{FeO}$ (or $\mathrm{Fe}_{3} \mathrm{O}_{4}$ ) in molten iron would substantially increase the oxygen fugacity of the mantle-core system, thereby increasing the concentrations of siderophile elements which entered the silicateoxide phases. The present modification of MAO's hypothesis, which introduces a small proportion of ferric iron into the mantle, would cause a further marked increase in the oxygen fugacity of this region, with a corresponding increase in the proportions of siderophile elements entering the silicate phase.

(e) Conclusion We have previously concluded that the outer core probably contains a large proportion of $\mathrm{FeO}$ (or $\mathrm{Fe}_{3} \mathrm{O}_{4}$ ) in solution. This would imply the presence of higher oxygen fugacities in the mantle during and after core- 
segregation than would have occurred if the segregating metal had consisted of pure iron. The higher oxygen fugacities may explain the high abundances of siderophile elements in the mantle in terms of equilibrium distributions between metal and silicate phases, followed by convective mixing of the silicates of the mantle during and subsequent to core formation. The same factors may account for the relatively high abundances of oxidized species in the mantle, e.g., $\mathrm{Fe}^{3+}, \mathrm{CO}_{2}$ and $\mathrm{H}_{2} \mathrm{O}$.

If these interpretations are confirmed by subsequent detailed investigations, the principal objections to the hypothesis that the earth formed by homogeneous accretion in the solar nebula from an intimate mixture of high temperature condensate $(\sim 90 \%)$ and low temperature condensate $(\sim 10 \%)$ will have been removed. Because of its comparative simplicity and its capacity to explain certain geochemical characteristics of the mantle not readily explained by heterogeneous accretion model, the homogeneous accretion hypothesis for the origin of the earth would occupy a preferred position.

Acknowledgements-I am indebted to Dr. R. ARCULUS, Dr. R. BRETT and Dr. S. KESSON for helpful comments and useful discussions.

\section{REFERENCES}

ADLER, D. (1969) Metal-nonmetal transitions in lowmobility materials. In Physical properties of solids under pressure, 165-177. CNRS, Grenoble.

AHRENS, T. J. (1976) Shock wave data for pyrrhotite and constraints on the composition of the outer core (abstract). U.S.-Japan Seminar on High-pressure Research Applications in Geophysics, 31.

ALDER, B. J. (1966) Is the mantle soluble in the core? J. Geophys. Res. 71, 4973-4979.

ANDERS, E. (1964) Origin, age and composition of meteorites. Space Sci. Rev. 3, 583-714.

ANDERS, E. (1968) Chemical processes in the early solar system as inferred from meteorites. Acc. Chem. Res. 1, 289-298.

ANDERS, E. (1971) Meteorites and the early solar system. Ann. Rev. Astron. Astrophys. 9, 1-34.

ANDERSON, D. L., SAMMIS, C. and JoRdAN, T. (1971) Composition and evolution of the mantle and core. Science 171, 1103-1112.

ARGOLLO, R. M. (1974) Ga-Al and Ge-Si in volcanic rocks. M.Sc. Thesis (unpublished). Univ. Rhode Island.

B AEDECKer, P. A., Shaudy, R., Elzie, J., KimberLIN, J. and W ASSON, J. (1971) Trace element studies of rocks and soils from Oceanus Procellarum and Mare Tranquillitatis. Proc. Second Lunar Sci. Conf. 2, 1037-1061.

BIRCH, F. (1952) Elasticity and constitution of the earth's interior. J. Geophys. Res. 57, 227-288.

BIRCH, F. (1963) Some geophysical applications of high pressure research. In Solids under pressure (editors W. PAUL and D. WARSCHAUER), 137162. McGraw-Hill, New York.

BIRCH, F. (1964) Density and composition of mantle and core. J. Geophys. Res. 69, 4377-4388.

BIRCH, F. (1965) Speculations on the earth's thermal history. Bull. Geol. Soc. Am. 76, 133-154.

BIRCH, F. (1966) Handbook of physical constants (editor S. P. C LARK), 118. 2nd Edition, Geol. Soc. Am. Mem. 97.

BIRCH, F. (1972) The melting relations of iron and temperatures in the earth's core. Geophys. J. 29, 373-387.

BODSWORTH, C. (1963) Physical chemistry of iron and steel manufacture. Longmans, England.

BRETT, R. (1971) The earth's core: Speculations on its chemical equilibrium with the mantle. Geochim. Cosmochim. Acta 35, 203-225.

BRETT, R. (1976) The current status of speculations on the composition of the core of the earth. Rev. Geophys. Space Phys. 14, 375-383.

BUKOWINSKI, M. S. (1976) The effect of pressure on the physics and chemistry of potassium. Geophys. Res. Lett. 3, 491-494.

BULLEN, K. E. (1973a) Cores of the terrestiral planets. Nature 243, 68-70.

BULLEN, K. E. (1973b) On planetary cores. The Moon 7, 384-395.

CAmeron, A. G. L. (1973) Abundances of the elements in the solar system. Space Sci. Rev. 15, 212146.

ClaRK, S. P. and RINGWood, A. E. (1964) Density distribution and constitution of the mantle. Rev. Geophys. 2, 35-88.

DAVIES, G. F. and GaFFneY, E. (1973) Identification of phases of rocks and minerals from Hugoniot data. Geophys. J. 33, 165-183.

De Maria, G., Balducci, G., Guido, M. and PIACENTE, V. (1971) Mass spectrometric investigation of the vapourization process of Apollo 12 lunar samples. Proc. Second Lunar Sci. Conf. 2, 13671380.

Dickinson, W. R. and LuTH, W. C. (1971) A model for plate tectonic evolution of mantle layers. Science 174, 400-404.

Distin, P. A., Whiteway, S. and Masson, C. (1971) Solubility of oxygen in liquid iron from $1785^{\circ}$ to $1960^{\circ}$. A new technique for the study of slag-metal equilibria. Canad. Metallurg. Quart. 10, 13-18. 
DubretseV , V. A. and Pan'Kov, V. (1972) On the composition of the earth's core. Izvestiya, Physics of the solid earth, No. 7, 48-54.

DZIEWONSKI, A. M., HALES, A. L. and LAPWOOD, E. R. (1975) Parametrically simple earth models consistent with geophysical data. Phys. Earth Planet. Interiors 10, 12-48.

Elliot, R. P. (1965) Constitution of binary alloys, First Supplement. McGraw-Hill, New York.

ELSASSER, W. M. (1963) Early history of the earth. In Earth science and meteoritics. (eds. J. GEISS and E. GolDBERG), 1-30, North-Holland, Amsterdam.

EVANS, R. C. (1966) An introduction to crystal chemistry. Cambridge Univ. Press, Cambridge. 410pp.

FREY, F. A., BRYAN, W. and THOMPSON, G. (1974) Atlantic Ocean Floor; geochemistry and petrology of basalts from Legs 2 and 3 of the Deep Sea Drilling Project. J. Geophys. Res. 79, 5507-5528.

FYFE, W. S. (1960) The possibility of d-electron coupling in olivine at high pressures. Geochim. Cosmochim. Acta 19, 141-143.

GANAPATHY, R. and ANDERS, E. (1974) Bulk compositions of the moon and earth estimated from meteorites. Proc. Fifth Lunar Sci. Conf. 2, 11811206.

GAST, P. W. (1960) Limitations on the composition of the upper mantle. J. Geophys. Res. 65, 12871297.

GibSON, E. K., HubBard, N., WieSmann, H., BANSAL, B. and Moore, G. (1973) How to lose Rb, K, and change the $\mathrm{K} / \mathrm{Rb}$ ratio: An experimental study. Proc. Fourth Lunar Sci. Conf. 2, 1263-1273.

GOETTEL, K. A. (1975) Potassium in the earth's core. Ph.D. Thesis. Mass. Inst. of Technology, Cambridge, Mass.

Goettel, K. A. and Lewis, J. S. (1973) Comments on a paper by V. M. OVERSBY and A. E. RINGWOOD. Earth Planet. Sci. Lett. 18, 148-150.

GoLDSCHMIDT, V. M. (1922) Über die Massenverteilung im Erdinneren, verglichen mit der Struktur gewisser Meteoriten. Naturwissenschaften 42, 1-3.

GoLES, G. C. (1967) Trace elements in ultramafic rocks. In Ultramafic and related rocks (editor P. J. WYLLIE), 352-362. Wiley, New York.

Grossman, L. A. (1972) Condensation in the primitive solar nebula. Geochim. Cosmochim. Acta 36, 597-619.

Grossman, L. A. and Larimer, J. (1975) Early chemical history of the solar system. Rev. Geophys. Space Phys. 12, 71-101.

GURNEY, J. J.and AHRENS, L. H. (1973) Zinc content of some ultramafic and basic rocks. Trans. Geol. Soc. South Africa 73, 301-307.

HALL, H. and MURTHY, V. R. (1971) Early chemical history of the earth: Some critical elemental frac- tionations. Earth Planet. Sci. Lett. 11, 239-244.

HANSEN, M. and ANDERKO, K. (1958) Constitution of binary alloys, 2nd Edition. McGraw-Hill, New York.

HAYES, J. M. (1967) Organic constituents of meteorites: A review. Geochim. Cosmochim. Acta 31, 1395-1440.

Higgins, G. H. and Kennedy, G. C. (1971) The adiabatic gradient and the melting point gradient in the core of the earth. J. Geophys. Res. 76, 18701878.

Holland, H. D. (1963) The origin and evolution of atmospheres and oceans (eidtors P. BRANCAZIO and A. G. W. CAMERON), 86-101. Wiley, New York.

ITO, K. (1976) Outer cores of the terrestrial planets: Eutectic melt hypothesis. Geochem. J. 10, 59-64.

JACOBS, J. A. (1975) The earth's core. Academic Press, New York.

Katsura, T., IwaSaKi, B. and Kimura, S. (1967) High pressure synthesis of the stoichiometric compound $\mathrm{FeO}$. J. Chem. Phys. 47, 4559-4560.

KNOPOFF, L. and MACDONALD, G. J. F. (1960) An equation of state for the core of the earth. Geophys. J. 3, 68-77.

KUBACHEWSKI, O. and EvANS, E. (1958) Metallurgical thermochemistry. Pergamon Press, London.

KusKov, O. L. and KhITAROV, N. I. (1974) On the chemical composition of the cores of the terrestrial planets and the moon. Proc. Soviet-American Conf. on the Cosmochemistry of the Moon and Planets. Moscow, 1976. In press.

LARIMER, J. W. (1975) The effect of C/O ratio on the condensation of planetary material. Geochim. Cosmochim. Acta 39, 389-392.

LEWIS, J. S. (1971) Consequences of the presence of sulfur in the core of the earth. Earth Planet. Sci. Lett. 11, 130-134.

LIU, L. (1974) Silicate perovskite from phase transformations of pyrope-garnet at high pressures and temperatures. Geophys. Res. Lett. 1, 277-280.

LIU, L. (1975) Post-oxide phases of forsterite and enstatite. ibid. 2, 417-419.

LiU, L. (1976) The high pressure phases of $\mathrm{MgSiO}_{3}$. Earth Planet. Sci. Lett. 31, 200-208.

MACDONALD, G. J. F. and KNOPOFF, L. (1958) The chemical composition of the outer core. Geophys. J. 1, 284-297.

MAO, H. K. (1974) A discussion of the iron oxides at high pressure with implications for the chemical and thermal evolution of the earth. Carnegie Inst. Washington Yearbook 73, 510-518.

MAO, H. K., TAKAHASHI, T., BASSETT, W., KINGSLAND, G., and MERRILL, L. (1974) Isothermal compression of magnetite to $320 \mathrm{kbar}$ and pressure-induced phase transformation. J. Geophys. Res. 79, 1165- 
1170.

MASON, B. (1963) The carbonaceous chondrites. Space Sci. Rev. 1, 621-646.

MASON, B. (1966) Composition of the earth. Nature 211, 616-618.

MASON, B. (1971) The carbonaceous chondrites - a selective review. Meteoritics 6, 59-70.

MASON, B. and WIIK, H. (1962) Description of two meteorites: Karoonda and Erakot. Am. Museum Novitates $2115,1-10$.

MCQueEN, R. G. and Marsh, S. (1966) Shock wave compression of iron-nickel alloys and the earth's core. J. Geophys. Res. 71, 1751-1756.

MUELleR, R. F. (1964) A comparison of oxidative equilibria in meteorites and terrestrial rocks. Geochim. Cosmochim. Acta 27, 273-278.

MURThY, R. V. and HALL, H. (1970) The chemical composition of the earth's core: Possibility of sulphur in the core. Phys. Earth Planet. Interiors 2, 276282.

OVersby, V. M. and RINGWOOD, A. E. (1972) Potassium distribution between metal and silicate and its bearing on the occurrence of potassium in the earth's core. Earth Planet. Sci. Lett. 14, 345-347.

OVERSBY, V. M. and RINGWOOD, A. E. (1973) Reply to comments by K. GoETTEL and J. S. LEWIS. ibid. 18, 151-152.

Rader, L. F., Swadley, W., HofFman, C. and LiPP, H. (1963) New chemical determinations of zinc in basalts and rocks of similar composition. Geochim. Cosmochim. Acta 27, 695-716.

RINGWOOD, A. E. (1958) Constitution of the mantle, 3. Consequences of the olivine-spinel transition. ibid. 15, 195-212.

RINGWOOD, A. E. (1959) On the chemical evolution and densities of the planets. ibid. 15, 257-283.

RINGWOOD, A. E. (1960) Some aspects of the thermal evolution of the earth. ibid. 15, 241-259.

RINGWOOD, A. E. (1963) The origin of high temperature minerals in carbonaceous chondrites. $J$. Geophys. Res. 68, 1141-1143.

RINGWOOD, A. E. (1966a) The chemical composition and origin of the earth. In Advances in earth science (editor P. M. HURLEY), 287-356. M̀IT Press, Mass.

RINGWOOD, A. E. (1966b) Chemical evolution of the terrestrial planets. Geochim. Cosmochim. Acta 30, 41-104.

RINGWOOD, A. E. (1966c) Genesis of chondritic meteorites. Rev. Geophys. 4, 113-175.

RINGWOOD, A. E. (1969) Composition and evolution of the upper mantle. In The earth's crust and upper mantle, 1-17. Am. Geophys. U. Mon., 13.

RINGWOOD, A. E. (1971) Core-mantle equilibrium: Comments on a paper by R. BRETT. Geochim.
Cosmochim. Acta 35, 223-230.

RINGWOOD, A. E. (1972) Phase transformations and mantle dynamics. Earth Planet. Sci. Lett. 14, 233241.

RINGWOOD, A. E. (1975) Composition and petrology of the earth's mantle. McGraw-Hill, New York.

RINGWOOD, A. E. (1977) Composition and origin of the earth. In preparation.

RingwoOd, A. E. and Kesson, S. E. (1977) Basaltic magmatism and the composition of the moon. Part II: Siderophile and volatile elements in the moon, earth and chondrites: Implications for lunar origin. The Moon. In press.

RUBEY, W. A. (1951) Geologic history of sea water. Bull. Geol. Soc. Am. 62, 1111-1147.

SATO, M., HiCKLiNG, N. and MCLANE, J. (1973) Oxygen fugacity values of Apollo 12, 14 and 15 samples and reduced state of lunar magmas. Proc. Fourth Lunar Sci. Conf. 1, 1061-1079.

SHANNON, R. C. and PREWITT, C. T. (1969) Effective ionic radii in oxides and fluorides. Acta Cryst. B25, 925-946.

Sherman, C. H., Elvander, H. and Chipman, J. (1950) Sulphur in molten Fe-S alloys. J. Metals 2, 334-340.

STEUBER, A. M. and Goles, G. (1967) Abundances of $\mathrm{Na}, \mathrm{Mn}, \mathrm{Cr}, \mathrm{Sc}$ and $\mathrm{Co}$ in ultramafic rocks. Geochim. Cosmochim. Acta 31, 75-93.

STEVENSON, D. J. (1977) Hydrogen in the earth's core. (Submitted for publication).

STRENS, R. G. (1969) The nature and geophysical importance of spin pairing in minerals of iron (II). In The application of modern physics to the earth and planetary interiors (editor S. K. RUNCORN), 213-216. Interscience (Wiley), New York.

TAYLOR, H. P., DUKE, M., SILVER, L. and EPSTEIN, S. (1965) Oxygen isotope studies of minerals in stony meteorites. Geochim. Cosmochim. Acta 29, 489512.

TOSSELL, J. A. (1976) Electronic structures of ironbearing oxidic minerals at high pressure. Am. Mineral. 61, 130-144.

TUREKIAN, K. and Clark, S. P. (1969) Inhomogeneous accumulation of the earth from the primitive solar nebula. Earth Planet. Sci. Lett. 6, 346-348.

UREY, H. C. (1952) The planets. Yale Univ. Press, New Haven.

WAI, C. M. and WASSON, J. T. (1977) Nebula condensation of moderately volatile elements and their abundances in ordinary chondrites. Earth Planet. Sci. Lett: In press.

WasserburG, G. J., MacDonald, G. J. F., Hoyle, F. and FowLER, W. (1964) Relative contributions of uranium, thorium and potassium to heat production in the earth. Science 143, 465-467. 
WASSON, J. T. and WAI, C. (1976) Explanation for the very low $\mathrm{Ga}$ and $\mathrm{Ge}$ concentrations in some iron meteorite groups. Nature 261, 114-116.

WEDEPOHL, K. (Editor) (1974) Handbook of geochemistry, II. Springer-Verlag, New York.
WIIK, H. B. (1956) The chemical composition of some stony meteorites. Geochim. Cosmochim. Acta 9, 279-289.

WooD, J. (1963) On the origin of chondrules and chondrites. Icarus 2, 152-180. 